\title{
The perception of handshapes in American Sign Language
}

\author{
STEPHANIE A. BAKER \\ Dartmouth College, Hanover, New Hampshire \\ WILLIAM J. IDSARDI and ROBERTA MICHNICK GOLINKOFF \\ University of Delaware, Newark, Delaware \\ and \\ LAURA-ANN PETITTO \\ Dartmouth College, Hanover, New Hampshire
}

\begin{abstract}
Despite the constantly varying stream of sensory information that surrounds us, we humans can discern the small building blocks of words that constitute language (phonetic forms) and perceive them categorically (categorical perception, CP). Decades of controversy have prevailed regarding what is at the heart of CP, with many arguing that it is due to domain-general perceptual processing and others that it is determined by the existence of domain-specific linguistic processing. What is most key: perceptual or linguistic patterns? Here, we study whether CP occurs with soundless handshapes that are nonetheless phonetic in American Sign Language (ASL), in signers and nonsigners. Using innovative methods and analyses of identification and, crucially, discrimination tasks, we found that both groups separated the soundless handshapes into two classes perceptually but that only the ASL signers exhibited linguistic CP. These findings suggest that CP of linguistic stimuli is based on linguistic categorization, rather than on purely perceptual categorization.
\end{abstract}

How do we discern the phonetic units that make up the constantly varying linguistic stream around us? One of the most researched answers to this question has been surrounded by controversy since the 1950s, when human adults were found to partition speech sounds from a continuum into discrete categories, a phenomenon known as categorical perception (CP; see Liberman, 1996, for a review). Early findings regarding the $\mathrm{CP}$ of speech sounds suggested that $\mathrm{CP}$ is specific to spoken language in humans and is the result of linguistic-specific processing. This special mechanisms hypothesis was supported by findings from two lines of research, the first of which was that $\mathrm{CP}$ occurred only for contrasts that were phonemic in a speaker's native language. For example, it has been shown that adult speakers of Japanese have difficulty distinguishing between $/ \mathrm{l} /$ and $/ \mathrm{r} /$ (Miyawaki et al., 1975), and Werker, Gilbert, Humphrey, and Tees (1981)

We thank the deaf and hearing individuals who participated in this study. We thank Baris Kabak for his assistance with preparing the PsyScope experiments, Kim Pudans-Smith for help in recruiting and testing deaf participants, and Karen Emmorey and Stephen McCullough for helpful design discussions. We also thank Ioulia Kovelman for help with the statistical analysis and Ulana Harasymowycz and Elizabeth Norton for invaluable assistance with the details of manuscript preparation. L.-A.P. thanks Dartmouth College for research funds. Correspondence concerning this article should be addressed to L.-A. Petitto, Department of Psychological and Brain Sciences and Department of Education, 305 Moore Hall, Dartmouth College, Hanover, NH 03755 (e-mail: laura-ann.petitto@dartmouth.edu). and Werker and Tees (1983) have also shown that English-speaking adults cannot discriminate the Hindi contrasts $/ \mathrm{t}^{\mathrm{h}} \mathrm{a} /-/ \mathrm{dh}^{\mathrm{h}} \mathrm{a}$ ( voiceless aspirated dental stop vs. breathy voiced) or $/ \mathrm{t}$ 'a/- $/ \mathrm{ta} /$ (voiceless unaspirated retroflex vs. dental) as well as Hindi adults can.

An earlier finding came from Eimas, Siqueland, Jusczyk, and Vigorito's (1971) work on 1-month-old infants' speech perception. They showed that infants could discriminate computer-generated sounds that straddled the adult phonetic boundary but failed to discriminate stimuli that were from within the same adult phonetic category. The infants' ability to do this without having had a long period of experience in listening to or producing speech suggested that $\mathrm{CP}$ was not learned and was, in fact, a part of the biological makeup of the human species. In addition, it has been well documented in the literature that infants can easily discriminate both native and nonnative oral consonant contrasts without having had relevant experience; however, by 10-12 months of age, infants perform like adults and easily discriminate only native consonant contrasts (see Jusczyk, 1997, for a review). There is a developmental shift in the perception of vowel contrasts as well, from a language-general processing pattern to a language-specific pattern, although this shift seems to occur earlier in development than does that for consonants (Polka \& Werker, 1994). This pattern of research findings has led to the hypothesis, first suggested by Eimas (1975), that infants may have a biological predisposition to discriminate the universal set of phonetic 
contrasts and that there is an apparent reorganization of this universal phonetic sensitivity as a result of their having learned a particular language.

This hypothesis that there is a specialized mode of speech processing in humans has been challenged by research demonstrating that certain nonhuman primates and animals also exhibit CP for human speech (Dooling, Best, \& Brown, 1995; Kluender, Diehl, \& Killeen, 1987; Kuhl, 1981, 1987; Kuhl \& Miller, 1975, 1978; Kuhl \& Padden, 1982, 1983; Ramus, Hauser, Miller, Morris, \& Mehler, 2000). In light of these findings, the hypothesis was changed to state that discrimination abilities for the processing of speech stimuli were a result of general auditory processing, rather than of a processing that had evolved specifically in humans for speech (Aslin \& Pisoni, 1980; Jusczyk, 1997).

Additional research has led to further refinement of the processing involved in $\mathrm{CP}$, since $\mathrm{CP}$ has been shown for nonlinguistic auditory and visual stimuli, such as sawtooth waves (plucking and bowing sounds; Jusczyk, Rosner, Cutting, Foard, \& Smith, 1977), pure tones (Pisoni, 1977), line length (Tajfel \& Wilkes, 1963), faces (Beale \& Keil, 1995), facial expressions (Calder, Young, Perrett, Etcoff, \& Rowland, 1996; Etcoff \& Magee, 1992; Young et al., 1997), facial actions (Campbell, Woll, Benson, \& Wallace, 1999), faces of different species (Campbell, Pascalis, Coleman, Wallace, \& Benson, 1997), and colors (Bornstein \& Korda, 1984; Boynton, Fargo, Olson, \& Smallman, 1989; Laws, Davies, \& Andrews, 1995; Özgen \& Davies, 2002; Pilling, Wiggett, Özgen, \& Davies, 2003; Roberson, Davies, \& Davidoff, 2000). In consideration of these findings, the current view is that the phonetic processing and categorization of speech is a result of domain-general processing common to perceptual systems (Kuhl, 2000). Thus, there is nothing specialized about the processing involved in $\mathrm{CP}$ for speech (i.e., language).

The nature of the processing involved in CP for linguistic stimuli remains an unresolved dilemma, however, since the general perceptual processing alternative fails to account for the fact that there are clear effects of linguistic experience on CP. Whereas infants perceive a wide range of phonetic contrasts in a categorical manner, adults perceive only those contrasts that are linguistically significant in their language. This type of differential CP is not true of other modalities (vision) or of the processing of nonlinguistic auditory stimuli. The question, "Is CP for language special?" resurfaces once again, although answering this question has been problematic, since "language" has primarily been studied using only speech. The argument for speech being special is that the processing underlying $\mathrm{CP}$ relies on phonetic representations of the sounds, as evidenced by language-specific $\mathrm{CP}$ speech effects, rather than on general auditory representations for the sounds, which would result in CP effects for all speech sounds, regardless of their phonemic status in the speaker's language. The confound that has arisen from using speech to study $\mathrm{CP}$ effects in language is that the auditory versus phonetic distinction for the processes driving linguistic $\mathrm{CP}$ has not been able to be teased apart experimentally, and contemporary science has been unable to adjudicate between the phonetic representation hypothesis and the general auditory representation hypothesis.

In an attempt to avoid the auditory versus phonetic confound for linguistic stimuli, researchers have turned to studying a visual language, American Sign Language (ASL). If the processing of visual stimuli is based solely on general perceptual processing, experience with a signed language should be of no consequence for $\mathrm{CP}$. That is to say, both people who have experience with sign language and people who have no experience with a signed language should exhibit $\mathrm{CP}$ effects for signed language contrasts, since everyone would have had experience with visual stimuli in general. Alternatively, linguistic experience could affect the processing of signed language contrasts by constraining perception on the basis of linguistic relevance. Thus, only those individuals who have had experience with a signed language should exhibit CP for the contrasts. This would mean that $\mathrm{CP}$, although not unique to speech, involves a unique interplay between linguistic and perceptual systems, since only those individuals with linguistic experience would have $\mathrm{CP}$ for visual linguistic contrasts.

The CP literature on signed language, however, provides conflicting results about the effect of linguistic experience with ASL. Supalla and Newport (1975; reported in Newport, 1982) investigated the phonetic parameters of location and handshape ${ }^{1}$ in ASL by varying one feature of a sign (place of articulation or handshape) along a continuum, while keeping all other features of the sign (e.g., facial expression and posture of the head) constant. Four continua were tested: two continua manipulating place of articulation and two continua manipulating handshape. The stimuli were movies that were $1 \mathrm{sec}$ long, followed by a 1 -sec visual mask of moving random lines. Participants completed both a labeling (identification) and an ABX discrimination task (ABX refers to the actual stimuli that are presented during the task; A and B are always different from each other, and the participant has to decide whether $\mathrm{X}$ is the same as $\mathrm{A}$ or $\mathrm{B}$ ).

The results of this study indicated that participants could label the stimuli that varied by handshape or place of articulation as belonging consistently to one category or another. Categorical perception was not found for any of the contrasts tested, however, since the participants were equally good at discriminating stimulus pairs both within and across the category boundary. Two possible explanations exist for these results. First, there may have been problems with the methodology: (1) The movies may have provided the participants with too many visual landmarks, since all of the signs were articulated on the face (i.e., the participants may have been measuring distances between the handshapes and the locations in relation to the signer's face); (2) the visual masks in between the trials may have been too simple to wipe out visual af- 
tereffects of the signs; (3) the visual mask presentation may have been too short $(1 \mathrm{sec})$ to degrade the visual aftereffects of the signs; and (4) only 4 participants were tested, which may have led to a lack of statistical power.

Second, it is possible that CP does not exist in ASL. Although CP does exist for spoken language, it is not necessarily characteristic of all language perception (e.g., vowels). This second explanation seems implausible, however, on the basis of the findings from $\mathrm{CP}$ experiments with colors and faces. It does not seem possible that both linguistic and nonlinguistic auditory stimuli and also nonlinguistic visual stimuli would exhibit CP but that linguistic visual stimuli would not. If $\mathrm{CP}$ is guided by general perceptual abilities, those same perceptual processes used to process nonlinguistic visual stimuli should be involved in the processing of visual stimuli that also happen to be linguistic.

More recently, Emmorey, McCullough, and Brentari (2003) did find CP effects for native deaf signers for phonologically contrastive hand configurations. ${ }^{2}$ Six continua were created over the course of two experiments. ${ }^{3}$ For each continuum, 11 still images were generated, depicting equally spaced steps along a continuum between two hand configurations or two places of articulation. The endpoint stimulus items for each continuum were entered into a computerized morphing program, and the computer morphed the intermediate handshape variants from one category to another. Each of the handshape variants for the continua was presented at body locations where the actual lexical signs occur. Native signing and nonsigning participants completed a binary forced choice identification task and an $\mathrm{ABX}$ discrimination task.

The results from the identification task indicated that both the signers and the nonsigners could reliably identify the hand configuration (regardless of phonological status) and the place of articulation stimuli as belonging to two distinct categories. The results from the discrimination task, however, showed that only the signers demonstrated $\mathrm{CP}$, and only for the phonologically contrastive hand configuration continua. Neither group exhibited $\mathrm{CP}$ for the place of articulation continua. These results suggest that deaf signers have developed special abilities for perceiving distinctions that are relevant to signed language. In addition, the fact that only deaf signers exhibited CP effects for contrastive ASL hand configurations suggests that "although humans may have special perceptual mechanisms for recognizing the human hand which allow for categorization, language experience plays an important role in the discrimination of hand configurations" (Emmorey et al., 2003, pp. 40-41).

The results of Emmorey et al.'s (2003) study are important because they establish CP with certain contrasts in a signed language. Given the conflicting results between Supalla and Newport (1975) and Emmorey et al., however, it remains unclear whether $\mathrm{CP}$ for handshape in ASL is a robust phenomenon, occurring across different types of stimuli (e.g., natural and/or synthetic) and multiple contrasts. The primary goal of the present study was to understand whether CP of linguistic stimuli is mediated by experience and whether this experience may be linguistic or perceptual.

To address the linguistic versus perceptual question, we asked whether CP effects exist for those handshapes that are contrastive (phonemic, distinctive) in ASL. We chose to focus solely on handshapes, due to a lack of CP effects for other types of linguistic contrasts in ASL (e.g., place of articulation; see Emmorey et al., 2003, for a discussion about $\mathrm{CP}$ and place of articulation). We hypothesized that if the processing for $\mathrm{CP}$ of linguistic stimuli is perceptual general (in this case, visual), both groups (signers and nonsigners) should exhibit CP for all of the handshapes. Alternatively, if the processing for $\mathrm{CP}$ of linguistic stimuli is mediated by linguistic experience, we hypothesized that only those people who have exposure to a signed language (signers) should exhibit CP for the handshapes.

How can we know whether a stimulus set is processed categorically? Is identifying stimuli as belonging to two separate groups enough? No, because identification indicates only that the participants can sort the stimuli into two groups but does not tell one whether they are sorting on the basis of a temporary representation of the perceptual properties of the stimuli (acoustic or visual) or making specific comparisons with stored representations of the categories along which the stimuli cohere (phonemic). Only discrimination can shed light on the nature of the representation. Thus, we used both the standard forced choice identification and the AX discrimination tasks to assess CP for the sign continua. The methodological innovation for this experiment in the data analysis of the present study is twofold. (1) Individual participant boundaries were calculated (as opposed to previous studies that averaged across all of the participants in a group) and were used as the basis for choosing the stimulus items for the discrimination task. This method ensured that each participant was tested on his or her own category boundary, in order to prevent discrimination abilities from being enhanced or diminished. ${ }^{4}$ (2) Discrimination abilities for within- and across-category judgments were calculated using signal detection theory (SDT; Green \& Swets, 1966), which has been modified to apply to situations in which participants are being asked to detect a difference between two signals (Macmillan \& Creelman, 1991), as is the case for the discrimination task in this study. SDT was chosen over the method that simply calculates the percentage of times that a participant correctly responds "same" or correctly responds "different" for each pair of stimulus items, since there is a serious weakness with this averaging approach. ${ }^{5}$ It would be possible for a participant to score $100 \%$ accuracy in detecting pairs that are different simply by answering "different" on all of the trials (the participant would then, of course, also score $0 \%$ accuracy on detecting pairs that 
are the same). To avoid having such a strong response bias, SDT was chosen in order to assign credit to only those situations in which the participants successfully distinguished among the different types of trials.

There were four possible SDT response outcomes for the discrimination task: (1) correct rejection of a difference, in which the participant correctly responded that there was no difference between the stimuli; (2) false alarm, in which the participant incorrectly responded that the stimuli were different; (3) miss, in which the participant responded that the stimuli were similar when they were different; and (4) hit, in which the participant correctly detected the difference between the stimuli. Then $d^{\prime}$ values were calculated for each participant, which included only the instances in which a participant correctly detected a difference in a stimulus pair (hits), rather than averaging across all of the instances (correct or incorrect) for a given participant. Note that for both the within- and the across-category judgments, a hit is defined as a different judgment, since the stimuli are, in fact, physically different from each other.

\section{METHOD}

\section{Participants}

The participants were 15 prelingually deaf adults who were native ASL signers (ASL group) and 15 hearing adults (English group) who had had no exposure to a signed language. All the deaf participants reported ASL as their primary and preferred language.

\section{Stimuli and Procedure}

Three phonemic handshape contrast pairs were used: [5]-[flat-0], [B-bar]-[A-bar], and [5]-[S]. ${ }^{6}$ The important implication for language processing and CP is that only phonemic distinctions produce CP effects. Thus, a given sound or handshape must appear in the set of phones for a language (i.e., the set of all possible sounds or handshapes for a particular language), and it must also be a part of the phonemic inventory (i.e., the set of sounds or handshapes used for lexical contrast) in order to be considered contrastive in a language (Brentari, 1995, 1998; Corina \& Sandler, 1993; Sandler, 1986, 1996; van der Hulst, 1995). We hypothesized that the adult deaf signers, unlike the hearing nonsigners, would have CP for these contrastive handshapes.

In order to create the visual homologue to classic spoken language perception experiments (e.g., Liberman, 1957), each handshape from the contrast pair became the endpoint of an 11-step continuum, depicting equally spaced steps between the two endpoints (Figure 1). ${ }^{7}$

The handshapes and their variants were articulated by a native deaf adult female signer standing against a black background and were digitally recorded. The head, torso, arm, and hand of the signer were visible, so as to anchor the hand to a body. Each handshape variant began with the handshape oriented so that the palm faced out toward the camera, and then the handshape was flipped so that the palm was toward the signer (see Figure 2). This movement occurred at a rate of $1.5 \mathrm{~Hz}$, or approximately one movement per second, since this had been shown to be the optimal rate of presentation for sign language processing (Petitto, Holowka, Sergio, \& Ostry, 2001). The videos were also sampled at a rate of $29.7 \mathrm{frames} / \mathrm{sec}$, consistent with previous research standards (Petitto et al., 2000). Although the handshapes were chosen from existing phonetic categories in ASL, the stimuli were meaningless phonetic units, analogous to [ba] and [pa] used for speech perception research. Thus, the signers could not use semantic information for any of their identification or discrimination judgments.

The stimuli were $4 \times 4 \mathrm{in}$. and were presented on a laptop computer with a 14-in. monitor, using PsyScope software (Cohen, MacWhinney, Flatt, \& Provost, 1993). All the participants performed two tasks: a forced choice identification task and an AX discrimination task.

Identification task. The three handshape continua tested were grouped into a block, and three blocks were presented. Each block consisted of three repetitions of each continuum, so that each handshape variant in a particular continuum was identified nine times by each participant across the entire experiment. The order of presentation of the continua within a block and of the trials within a continuum was also randomized across participants.

At the start of the identification task for a continuum, each participant was shown the two handshape endpoints side by side for $6 \mathrm{sec}$. The endpoint images were available to the participants only at the beginning of a given continuum, and not during the actual identification trials. For each identification trial, the participants were presented with a single handshape randomly selected from the 11 variants and were asked to decide which one of the endpoints (the one on the left or the one on the right) the current handshape more closely resembled. The participants pressed designated keys on the keyboard to indicate their response.

Discrimination task. We used the standard AX discrimination task that has been used in the field of speech perception (i.e., a stimulus item is presented, followed by an interstimulus interval [ISI], and then a second stimulus item is presented; the participant's task is to decide whether the second stimulus item is the same as the first $[\mathrm{A}]$ or different from the first $[\mathrm{X}]$ ). The same stimuli from the identification task were used here. The discrimination pairs were set around the actual boundary range for each individual participant, and not the average range across all the participants. Because the participants placed their boundary in approximately the same place (see Appendix A for a full listing of participant boundary placements by continuum), a small number of pairs from both sides of the boundary could be selected to encompass each participant's boundary. One of the pairs straddled the boundary for a given participant, and the three remaining pairs would fall from within the same category. For example, if a participant's boundary was located at 4.5 , the pairs $2 / 4,5 / 7$, and $7 / 9$ were all within-category judgments, whereas the $4 / 6$ pair was the across-category judgment. In addition, for each handshape that was a member of a nonidentical pair, an identical pair was also created for that handshape. Table 1 provides the specific pairings for each continuum.

Each pair of physically different stimuli was presented 10 times ( 5 times for each ordering), whereas the physically identical pairs were presented 5 times each. Each handshape was presented for $1,500 \mathrm{msec}$, with an ISI of $2,500 \mathrm{msec}$ and an intertrial interval of $1,000 \mathrm{msec}$. In order to decrease the chance that the participants were measuring the distances between the handshapes, each handshape appeared in a different location on the computer monitor, and the presentation of the handshape pairs was randomized across all of the contrasts. The participants pressed designated keys on the keyboard to indicate whether the second handshape was the same as or different from the first handshape.

\section{RESULTS}

For all three continua tested, both the ASL and the English groups identified the stimuli as belonging to distinct categories, with a sharp boundary between them (Figures 3A-3C). In addition, the boundaries between the categories were the same for both groups. Thus, both groups had the potential to perceive the handshapes categorically. However, since identification could occur 
[5]-[flat-0]

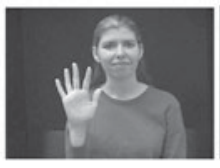

\#1

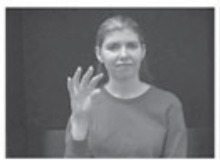

\#5

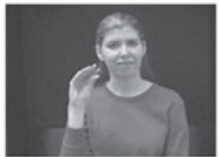

\#9

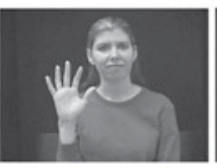

\#2

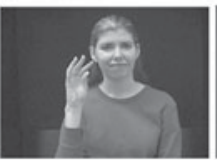

\#6

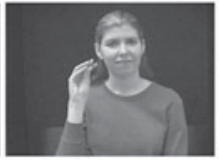

\#10

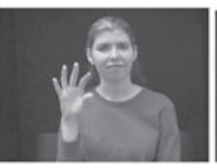

\#3

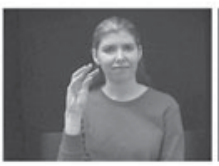

\#7

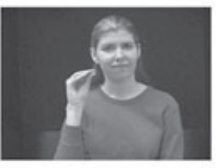

\#11

[B-bar]-[A-bar]

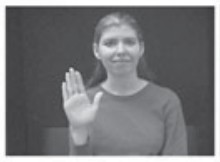

\#1

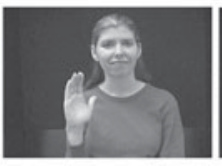

\#2

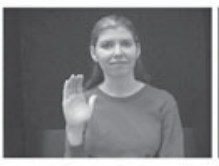

\#3

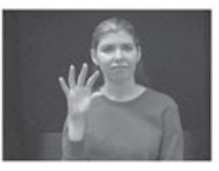

\#4

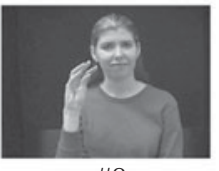

\#8

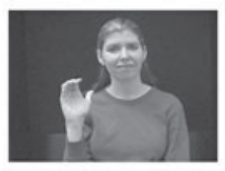

\#5

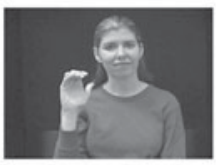

\#6

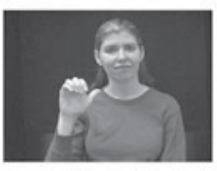

\#7

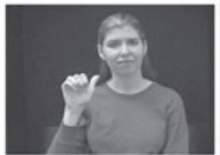

\#9

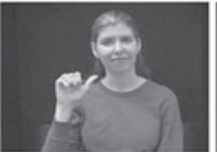

\#10

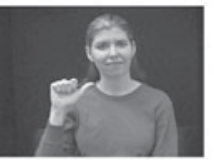

\#11

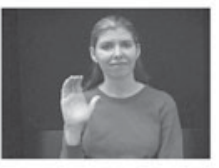

\#4

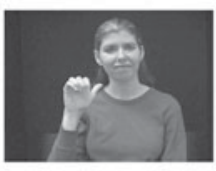

\#8

$[5]-[\mathrm{S}]$

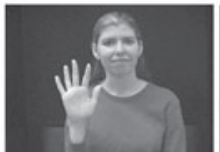

\#1

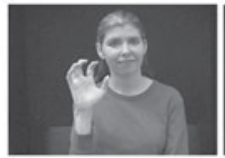

\#5

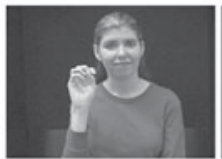

\#9

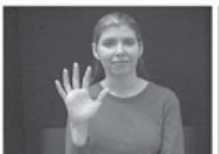

\#2

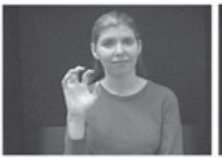

\#6

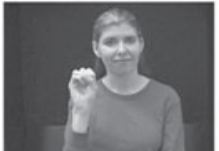

\#10

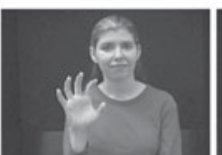

\#3

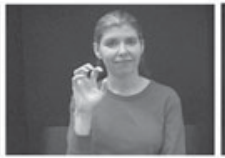

\#7

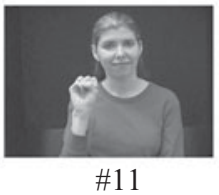

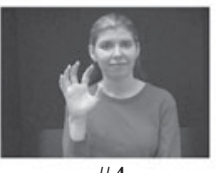

\#4

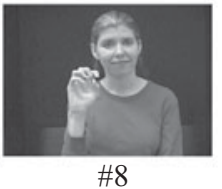

\#8

Figure 1. Handshape continua. The top set of images is the [5]-[flat-0] continuum, the center set of images is the [B-bar]-[A-bar] continuum, and the bottom set of images is the $[5]-[S]$ continuum. 

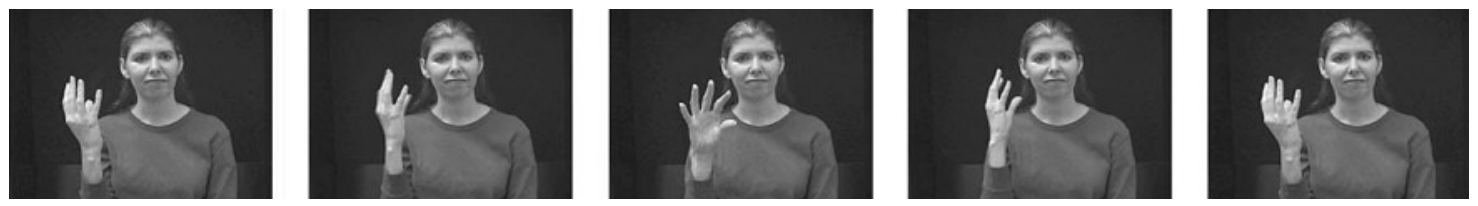

Figure 2. Sample stimuli movement cycle from the [5]-[flat-0] continuum.

through a perceptual sorting process, these data alone cannot be used to argue for CP effects (Damper \& Harnad, 2000; Massaro, 1987). By contrast, the process of discriminating between two stimulus items requires the existence of linguistic categories against which the stimuli are being compared.

For discrimination, the results indicate that only the ASL group had CP for the handshapes. The critical research question involving $\mathrm{CP}$ was whether there are differences in discrimination for those contrast pairs that are from within the same category, versus those contrast pairs that are from across a category boundary. If $\mathrm{CP}$ exists, discrimination must be heightened when pairs are from across a category boundary. In order to assess the participants' detection of differences between the stimuli, two sets of analyses were conducted. In the first analysis, SDT (Green \& Swets, 1966) was used, and $d^{\prime}$ scores were calculated for each participant, one for withincategory pairs and one for across-category pairs (Macmillan \& Creelman, 1991). This was the most straightforward way of looking at whether or not $\mathrm{CP}$ effects were observed, since the average of the across-category pairs should be higher than the average of the within-category pairs if participants have $\mathrm{CP}$ for the handshape contrasts. In the second analysis, SDT was also used, but this time $d^{\prime}$ scores were calculated for each participant for each handshape pair from a continuum, to ensure that any $\mathrm{CP}$ effects that were observed were not due to certain pairs or ends of a given continuum having enhanced or diminished discrimination.

\section{Within-Category Versus Across-Category Analysis}

We conducted a $3 \times 2 \times 2$ mixed analysis of variance (ANOVA) on $d^{\prime}$ values, with handshape contrast ([5][flat-0], [B-bar]-[A-bar], or [5]-[S]) and category membership (within or across) as the within-subjects factors and group as the between-subjects factor. This analysis (using an alpha level of .05) revealed no main effect for group $\left[F(1,28)=0.173, M S_{\mathrm{e}}=0.146, p>.680\right.$, n.s. $]$, which indicated that the participants in both groups were performing comparably in all of the conditions. This in- dicated that the nature of the task was not inherently more difficult (or easier) for one group than for another, which was expected. There were main effects for handshape contrast $\left[F(2,56)=5.000, M S_{\mathrm{e}}=2.311, p<.010\right]$ and for category membership [within vs. across; $F(1,28)=$ $\left.48.082, M S_{\mathrm{e}}=8.929, p<.001\right]$. Two-way interaction effects were found for group $\times$ category membership [within vs. across; $F(1,28)=91.587, M S_{\mathrm{e}}=17.008, p<$ $.001]$ and for handshape contrast $\times$ category membership [within vs. across; $F(2,56)=11.950, M S_{\mathrm{e}}=2.419$, $p<.001]$. Thus, differences of the same magnitude between the stimuli were perceived better when those stimuli crossed a category boundary for certain contrasts. An additional three-way interaction was found: group $\times$ category membership (within vs. across) $\times$ handshape contrast ([5]-[flat-0], [B-bar]-[A-bar], or [5]-[S]) $[F(2,56)=$ $16.405, M S_{\mathrm{e}}=3.320, p<.001$; Figures $\left.4 \mathrm{~A}-4 \mathrm{C}\right]$. Table 2 shows the means and standard errors and the 95\% confidence intervals for the ASL and English groups.

Due to the three-way interaction, an additional 3 (handshape contrast: [5]-[flat-0], [B-bar]-[A-bar], or [5]$[\mathrm{S}]) \times 2$ (category membership: within or across) repeated measures ANOVA was conducted separately for each group. For the ASL group, main effects were found for handshape contrast $\left[F(2,28)=4.498, M S_{\mathrm{e}}=1.510\right.$, $p<.014]$ and for category membership $[F(1,14)=$ $\left.160.154, M S_{\mathrm{e}}=25.292, p<.001\right]$. An additional twoway interaction was found for handshape contrast $\times$ category membership $\left[F(2,28)=24.512, M S_{\mathrm{e}}=0.230, p<\right.$ $.001]$. For the English group, no main effects or interactions were observed [handshape contrast, $F(2,28)=$ $2.619, M S_{\mathrm{e}}=1.622, p>.091$; category membership, $F(1,14)=3.022, M S_{\mathrm{e}}=0.645, p>.104$; handshape contrast $\times$ category membership, $F(2,28)=0.553, M S_{\mathrm{e}}=$ $0.175, p>.581]$. Thus, it is the ASL group that accounts for the differences observed in the three-way interaction reported above.

Planned comparisons revealed that the ASL group's within-category $d^{\prime}$ values were significantly different from the across-category $d^{\prime}$ values only for the handshape contrasts [5]-[flat-0] [t(14) $=-7.675, p<.001$,

Table 1

Discrimination Items

\begin{tabular}{lccl}
\hline \multicolumn{1}{c}{ Continuum } & $\begin{array}{c}\text { Boundary } \\
\text { Range }\end{array}$ & $\begin{array}{c}\text { Stimulus Pairs: } \\
\text { Nonidentical }\end{array}$ & Stimuli Pairs: Identical \\
\hline [5]-[flat-0] & $4.5-6.5$ & $2 / 4,4 / 6,5 / 7,7 / 9$ & $2 / 2,4 / 4,5 / 5,7 / 7,6 / 6$ \\
[B-bar]-[A-bar] & $4.5-6.5$ & $2 / 4,4 / 6,5 / 7,7 / 9$ & $2 / 2,4 / 4,5 / 5,7 / 7,6 / 6$ \\
[5]-[S] & $4.5-7.5$ & $2 / 4,4 / 6,6 / 8,8 / 10$ & $2 / 2,4 / 4,6 / 6,8 / 8,10 / 10$ \\
\hline
\end{tabular}




\section{[5]-[flat-0] Identification}

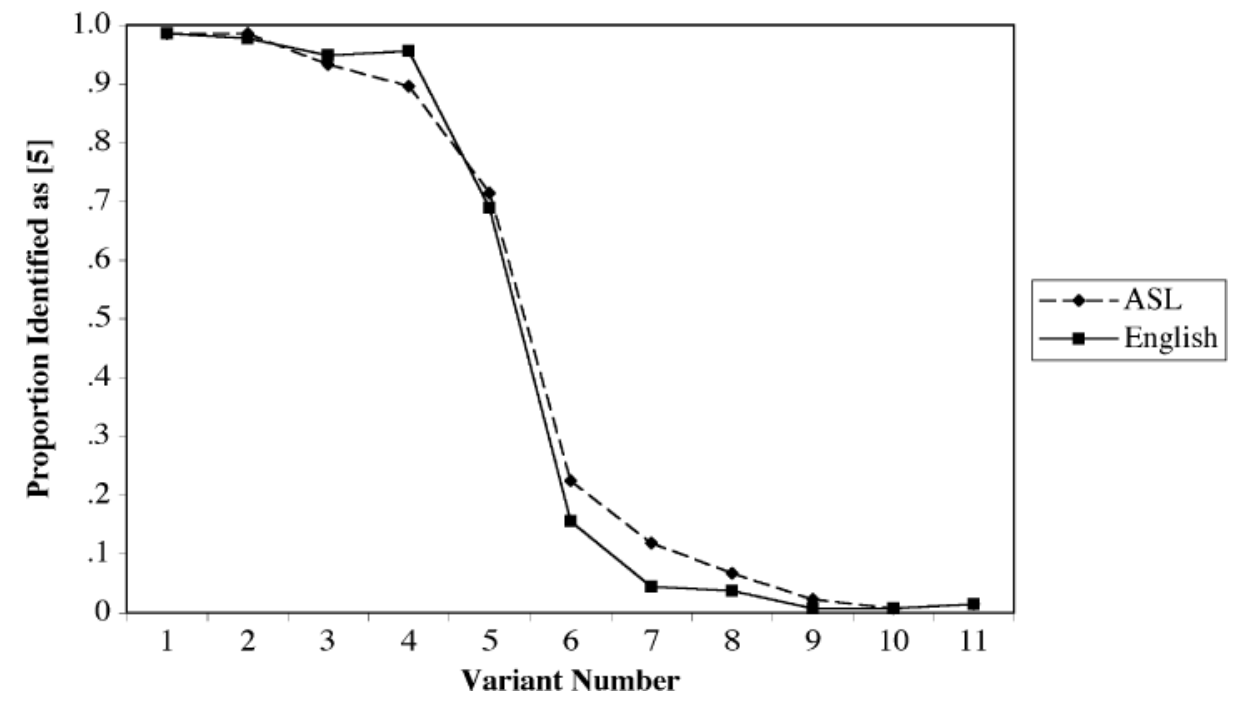

Figure 3A. Identification functions for the [5]-[flat-0] continuum.

two-tailed] and [B-bar]-[A-bar] [t(14) $=-9.059, p<$ .001 , two-tailed]. The within-category $d^{\prime}$ value was not significantly different from the across-category $d^{\prime}$ value for the [5]-[S] contrast $[t(14)=-0.590, p>.565$, n.s., two-tailed].

\section{Individual Pairs Analysis}

Despite the fact that the within-category values were significantly lower than the across-category values for the ASL group, it could be the case that the effect was being caused by certain pairs being more or less discriminable than others across a given continuum. It is also possible that not all of the pairs were equally dis- criminable for the English group, despite the fact that there were no statistically significant differences between the within- and the across-category judgments, since several pairs were averaged together for the withincategory judgment. For the ASL group, a 3 (handshape contrast: [5]-[flat-0], [B-bar]-[A-bar], or [5]-[S]) $\times 4$ (pairs: 2/4, 4/6, 5/7, or 7/9, [5]-[flat-0] and [B-bar]-[Abar]; $2 / 4,4 / 6,6 / 8$, or $8 / 10,[5]-[\mathrm{S}])$ repeated measures ANOVA was conducted. This analysis (alpha level of $.05)$ revealed no main effects for handshape contrast $[F(2,28)=2.153, p>.135$, n.s. $]$. A main effect was found for pair $[F(3,42)=23.525, p<.001]$, and a twoway interaction effect was found for handshape contrast $X$

\section{[B-bar]-[A-bar] Identification}

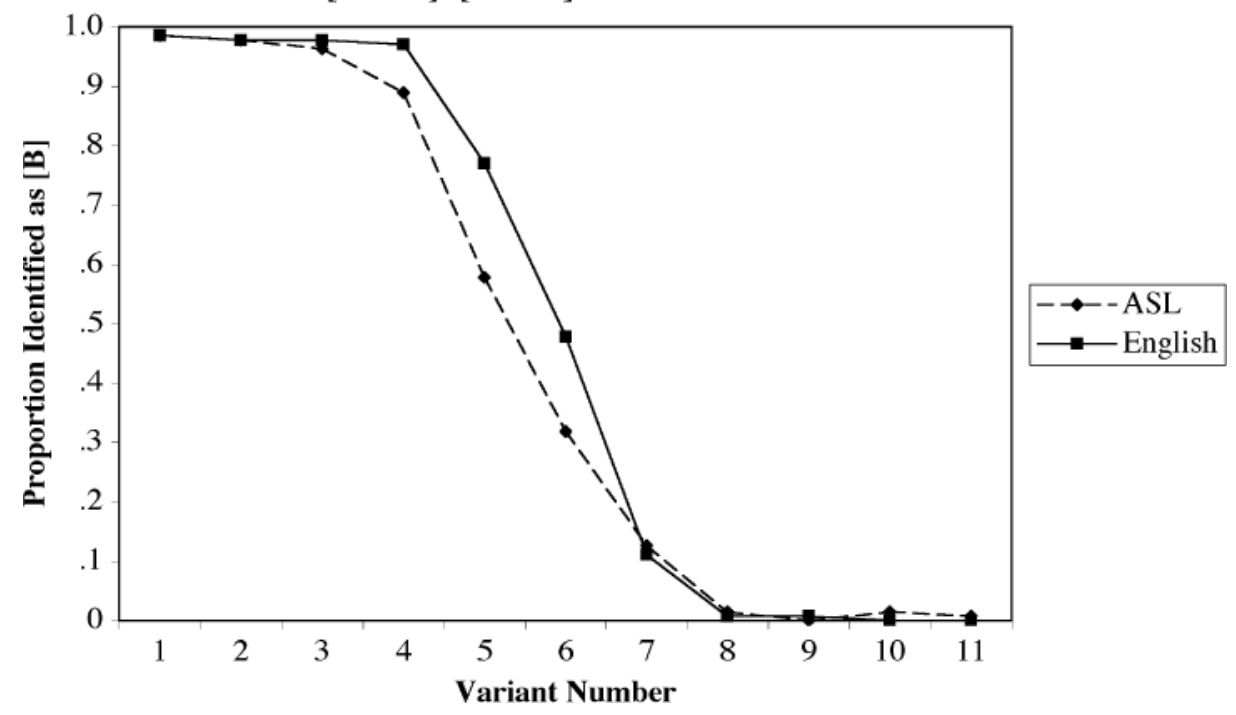

Figure 3B. Identification functions for the [B-bar]-[A-bar] continuum. 


\section{[5]-[S]Identification}

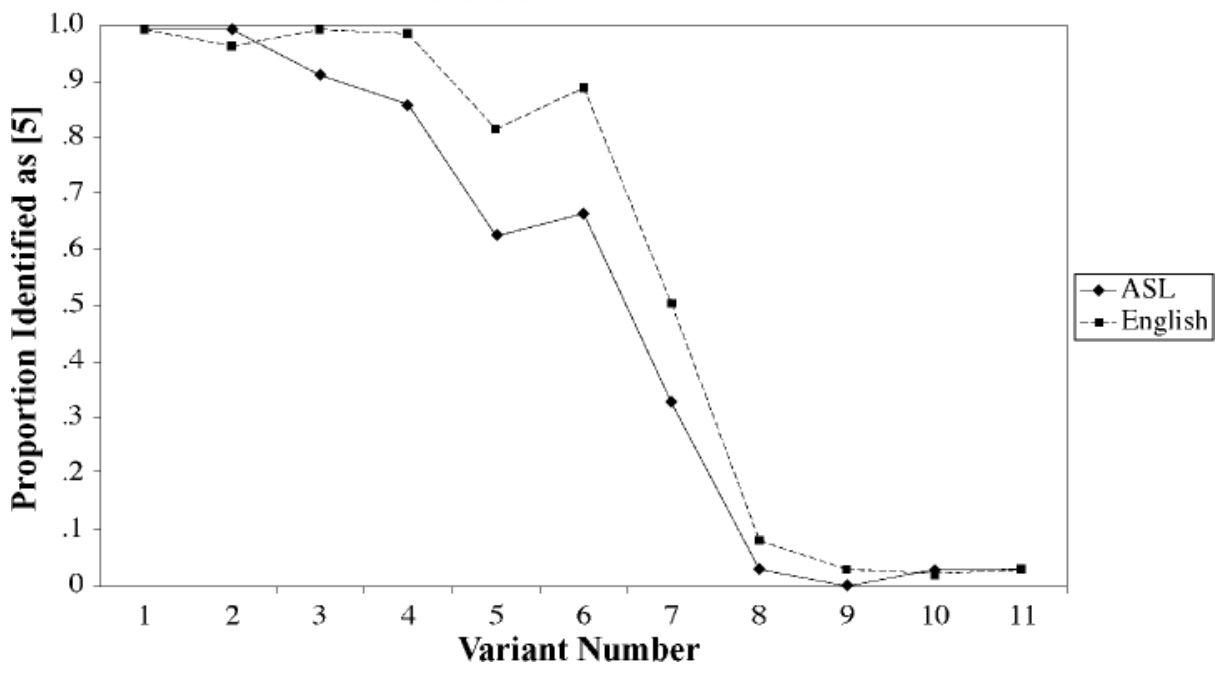

Figure 3C. Identification functions for the [5]-[S] continuum.

pair $[F(6,84)=14.251, p<.001]$. For the English group, a 3 (handshape contrast: [5]-[flat-0], [B-bar]-[A-bar], or [5]-[S]) $\times 4$ (pairs: $2 / 4,4 / 6,5 / 7$, or $7 / 9$, [5]-[flat-0] and [B-bar]-[A-bar]; 2/4, 4/6, 6/8, or 8/10, [5]-[S]) repeated measures ANOVA was conducted. This analysis $(\alpha=.05)$ revealed main effects for handshape contrast $[F(2,28)=$ $10.531, p<.001]$ and for pair $[F(3,42)=8.864, p<$ $.001]$. An additional two-way interaction effect was found for handshape contrast $\times$ pair $[F(6,84)=3.923, p<$
$.002]$. Thus, on the basis of the two-way interactions for both groups, the pairs were not equally discriminable across a given handshape contrast continuum, and the participants had differential performance across the continua. Table 3 lists the means, standard errors, and the $95 \%$ confidence intervals for the ASL and English groups.

Planned comparisons $(\alpha=.01)$ were conducted separately by group on each of the pairs from a contrast continuum, in order to determine which of the pairs across a

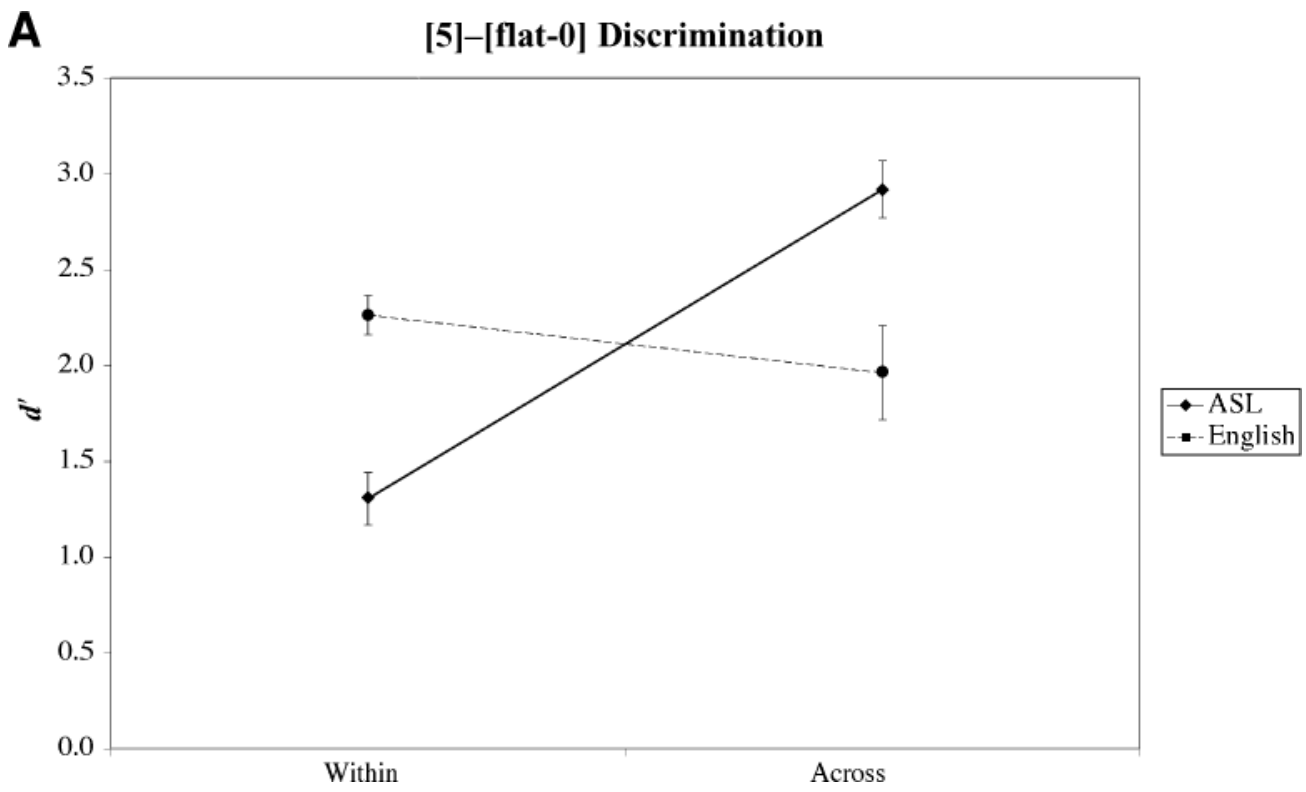

Figures 4A-4C. Group $\times$ category membership $\times$ contrast interactions. The mean $d^{\prime}$ values for the American Sign Language (ASL) group increase dramatically across the category boundary for (A) the [5]-[flat-0] and (B) the [B-bar]-[A-bar] contrasts, an indication that this group has categorical perception for these handshapes. Most notably, the mean $d^{\prime}$ values for the ASL group for (C) the [5]-[S] contrast do not increase across a category boundary, most likely due to the presence of an intermediate handshape category. The mean $d^{\prime}$ values for the English group decrease slightly across the category boundary for all of the contrasts, but this decrease is not significant (it is statistically not distinguished from a flat line). 


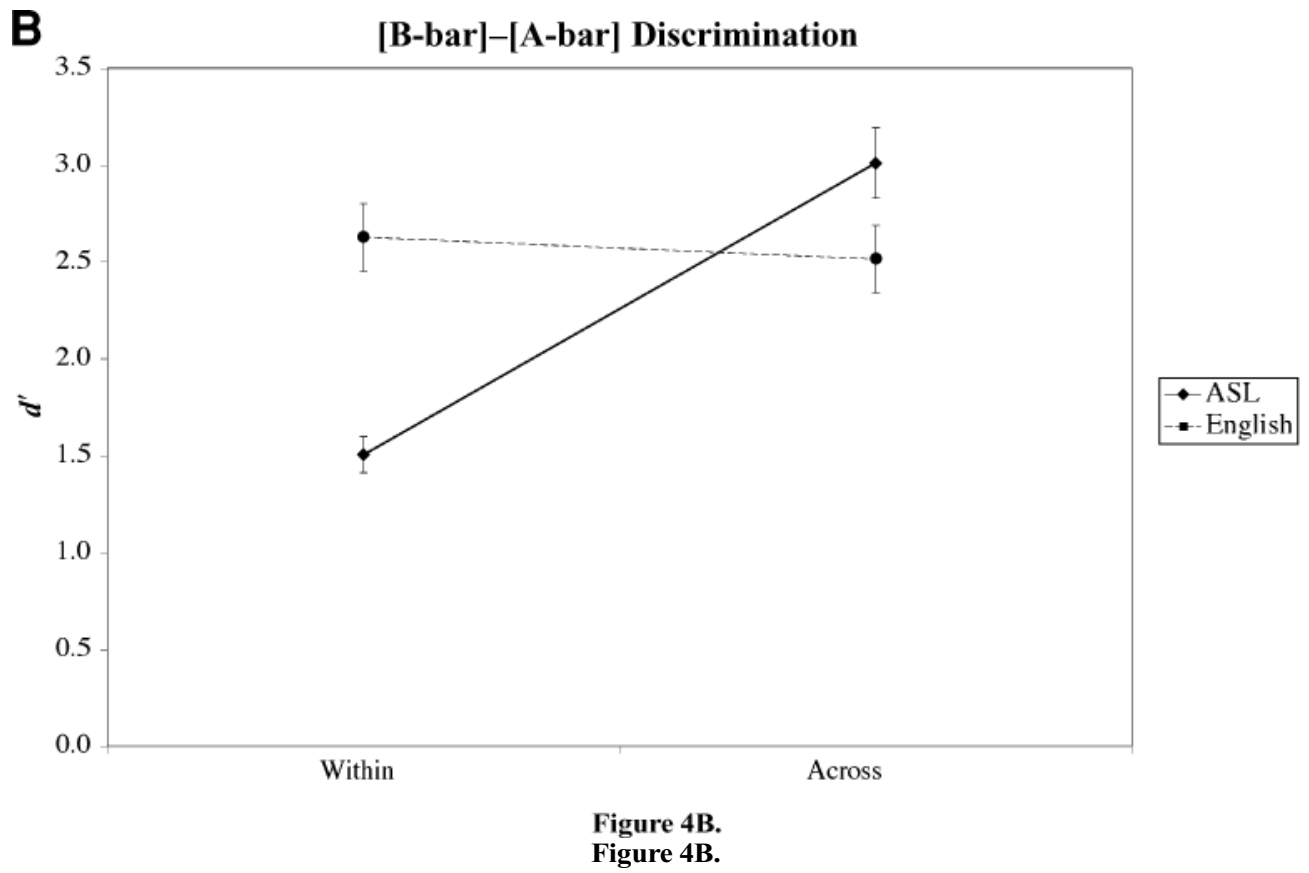

continuum were significantly different from each other. Specifically, if CP effects were present, it was expected that the within-category pairs would not be significantly different from each other, whereas the between-category pairs would be significantly different from their corresponding within-category pairs (e.g., 4/6 would be significantly different from $2 / 4$, and $5 / 7$ would be significantly different from $7 / 9$, whereas $2 / 4$ and $7 / 9$ would not be significantly different from each other). Individual pair comparisons and their statistical values are listed in Appendix B and are shown in Figures 5A-5F. Individual $d^{\prime}$ values by participant for each pair are listed in Appendix C.

For the ASL group on the [5]-[flat-0] and the [Bbar]-[A-bar] contrasts, the pairs were significantly different from each other $[F(3,42)=15.243, p<.001$, and $F(3,42)=23.158, p<.001$, respectively; Figures $5 \mathrm{~A}$ and $5 \mathrm{~B}]$. The within-category handshape pairs had equivalent discrimination values, whereas both of the between-category handshape pairs had significantly higher discrimination values than did the corresponding within-category handshape pairs. This type of differen-

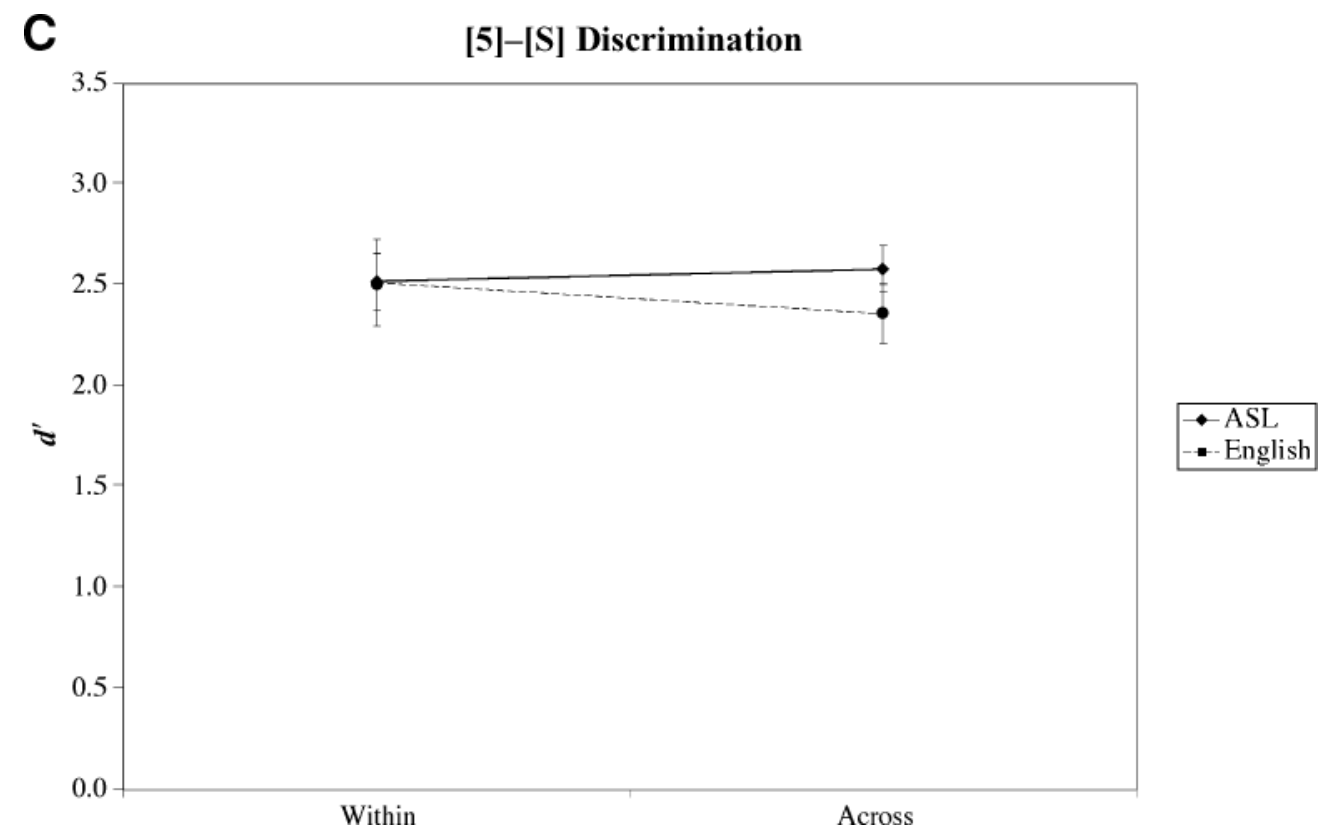

Figure 4C. 
Table 2

Group by Category Membership by Contrast Summary

\begin{tabular}{|c|c|c|c|c|c|c|}
\hline \multirow[b]{2}{*}{ Group } & \multirow[b]{2}{*}{ Contrast } & \multirow{2}{*}{$\begin{array}{c}\text { Category } \\
\text { Membership }\end{array}$} & \multirow[b]{2}{*}{$M$} & \multirow[b]{2}{*}{$S E$} & \multicolumn{2}{|c|}{ 95\% Confidence Interval } \\
\hline & & & & & Lower Bound & Upper Bound \\
\hline \multirow[t]{6}{*}{$\overline{\mathrm{ASL}}$} & {$[5-0]$} & Within & 1.305 & 0.121 & 1.057 & 1.552 \\
\hline & & Across & 2.919 & 0.203 & 2.504 & 3.334 \\
\hline & {$[\mathrm{B}-\mathrm{A}]$} & Within & 1.505 & 0.139 & 1.219 & 1.790 \\
\hline & & Across & 3.010 & 0.178 & 2.644 & 3.376 \\
\hline & {$[5-\mathrm{S}]$} & Within & 2.522 & 0.181 & 2.151 & 2.893 \\
\hline & & Across & 2.583 & 0.132 & 2.311 & 2.854 \\
\hline \multirow[t]{6}{*}{ English } & [5-0] & Within & 2.263 & 0.121 & 2.015 & 2.510 \\
\hline & & Across & 1.963 & 0.203 & 1.548 & 2.378 \\
\hline & {$[\mathrm{B}-\mathrm{A}]$} & Within & 2.627 & 0.139 & 2.342 & 2.913 \\
\hline & & Across & 2.515 & 0.178 & 2.150 & 2.881 \\
\hline & {$[5-\mathrm{S}]$} & Within & 2.457 & 0.181 & 2.086 & 2.828 \\
\hline & & Across & 2.361 & 0.132 & 2.089 & 2.632 \\
\hline
\end{tabular}

tial discrimination is expected with CP: Pairs that straddle a category boundary should be easier to discriminate than those that are from within the same category. ${ }^{8}$ For the [5]-[S] contrast, the pairs were also significantly different from each other $[F(3,42)=14.539, p<.001$; Figure $5 \mathrm{C}]$. For this continuum, however, the participants had heightened discrimination abilities across this continuum, with only the very last pair having significantly decreased discrimination in comparison with all of the other pairs.

For the English group on the [5]-[flat-0] and the [Bbar]-[A-bar] contrasts, the pairs were also significantly different from each other $[F(3,42)=12.597, p<.001$, and $F(3,42)=7.442, p<.001$, respectively; Figures 5D and $5 \mathrm{E}]$. For the [5]-[flat-0] contrast, the discrimination increased from one end of the continuum to the other in a linear fashion, and for the [B-bar]-[A-bar] contrast, the across-category pairs were significantly different from each other but were not significantly different from their respective within-category pairs. For the [5]-[S] contrast, the pairs were not significantly different from each other $[F(3,42)=0.917, p>.441$, n.s.; Figure 5F], with all of the handshape pairs being equally discriminable across the continuum. Despite the significant trends for two of the continua for the English group, these functions did not resemble the functions for the ASL group on the [5]-[flat-0] and the [B-bar]-[A-bar] contrasts, the functions for which the ASL group exhibited CP effects. Thus, although the English group may have had differential discrimination across a continuum, the discrimi-

Table 3

Handshape Pair by Contrast Interaction Summary

\begin{tabular}{lcccccc}
\hline \multirow{4}{*}{ Group } & Contrast & Pair & $M$ & $S E$ & Lower Bound & Upper Bound \\
\hline ASL & {$[5-0]$} & $2-4$ & 1.317 & 0.182 & 0.927 & 1.706 \\
& {$[5-0]$} & $4-6$ & 2.105 & 0.108 & 1.873 & 2.338 \\
& {$[5-0]$} & $5-7$ & 2.299 & 0.136 & 2.007 & 2.590 \\
& {$[5-0]$} & $7-9$ & 1.783 & 0.116 & 1.534 & 2.032 \\
& {$[\mathrm{~B}-\mathrm{A}]$} & $2-4$ & 1.499 & 0.098 & 1.289 & 1.710 \\
& {$[\mathrm{~B}-\mathrm{A}]$} & $4-6$ & 2.343 & 0.141 & 2.040 & 2.645 \\
& {$[\mathrm{~B}-\mathrm{A}]$} & $5-7$ & 2.097 & 0.127 & 1.824 & 2.369 \\
& {$[\mathrm{~B}-\mathrm{A}]$} & $7-9$ & 1.616 & 0.073 & 1.460 & 1.772 \\
& {$[5-\mathrm{S}]$} & $2-4$ & 2.702 & 0.218 & 2.235 & 3.169 \\
& {$[5-\mathrm{S}]$} & $4-6$ & 2.505 & 0.109 & 2.270 & 2.739 \\
& {$[5-\mathrm{S}]$} & $6-8$ & 2.391 & 0.163 & 2.041 & 2.742 \\
& {$[5-\mathrm{S}]$} & $8-10$ & 1.557 & 0.099 & 1.344 & 1.769 \\
Englishyynn & {$[5-0]$} & $2-4$ & 1.637 & 0.088 & 1.448 & 1.825 \\
& {$[5-0]$} & $4-6$ & 1.929 & 0.131 & 1.649 & 2.209 \\
& {$[5-0]$} & $5-7$ & 2.116 & 0.149 & 1.796 & 2.436 \\
& {$[5-0]$} & $7-9$ & 2.254 & 0.139 & 1.956 & 2.552 \\
& {$[\mathrm{~B}-\mathrm{A}]$} & $2-4$ & 2.701 & 0.162 & 2.353 & 3.050 \\
& {$[\mathrm{~B}-\mathrm{A}]$} & $4-6$ & 2.933 & 0.149 & 2.613 & 3.254 \\
& {$[\mathrm{~B}-\mathrm{A}]$} & $5-7$ & 2.557 & 0.174 & 2.182 & 2.931 \\
& {$[\mathrm{~B}-\mathrm{A}]$} & $7-9$ & 2.499 & 0.183 & 2.107 & 2.892 \\
& {$[5-\mathrm{S}]$} & $2-4$ & 2.316 & 0.197 & 1.894 & 2.738 \\
& {$[5-\mathrm{S}]$} & $4-6$ & 2.188 & 0.256 & 1.639 & 2.737 \\
& {$[5-\mathrm{S}]$} & $6-8$ & 2.218 & 0.181 & 1.831 & 2.605 \\
{$[5-\mathrm{S}]$} & $8-10$ & 2.347 & 0.173 & 1.977 & 2.718 \\
\hline
\end{tabular}




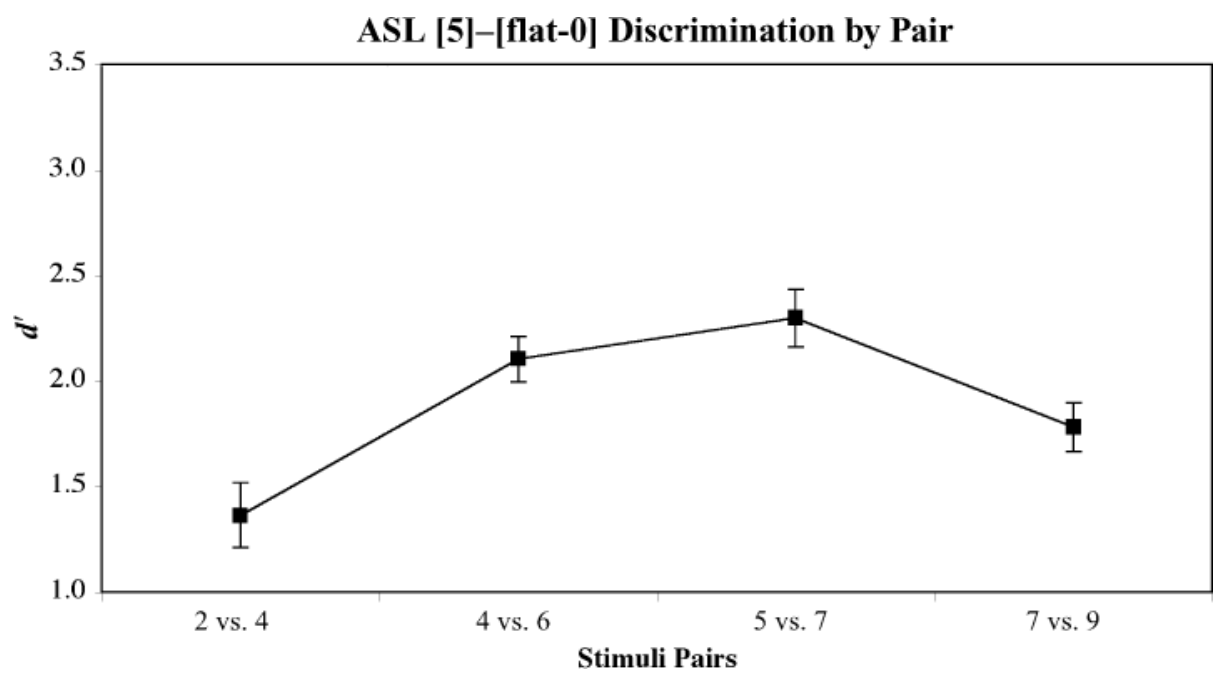

Figure 5A. The $d^{\prime}$ values by pair for the American Sign Language (ASL) group for the [5]-[flat-0] continuum.

nation did not reflect sensitivity to category boundaries, as it did for the ASL group on the [5]-[flat-0] and the [B-bar]-[A-bar] contrasts.

\section{DISCUSSION}

In the present experiment, we applied a method widely used in the field of speech perception, signal detection analysis, to investigate whether ASL has CP and whether these effects are mediated by linguistic experience. Although the ASL and the English participants divided the handshapes into two separate groups in the identification task, this was not surprising. This finding is consistent with previous research from Lane, Boyes-Braem, and Bellugi (1976), who found that both deaf signers (native and nonnative) and hearing nonsigners made the same types of visual confusions among the handshapes, suggesting that linguistic experience does not affect the ability to detect visual features involved in identifying handshapes. The present finding is also consistent with the results of Emmorey et al. (2003), where all of the participants could divide up the continua for hand configuration and place of articulation, and in approximately the same place along the continuum. Visual perception of handshapes, therefore, most likely guides this process of identification.

Because discrimination is the field's yardstick for attributions of $\mathrm{CP}$, the results from the discrimination task

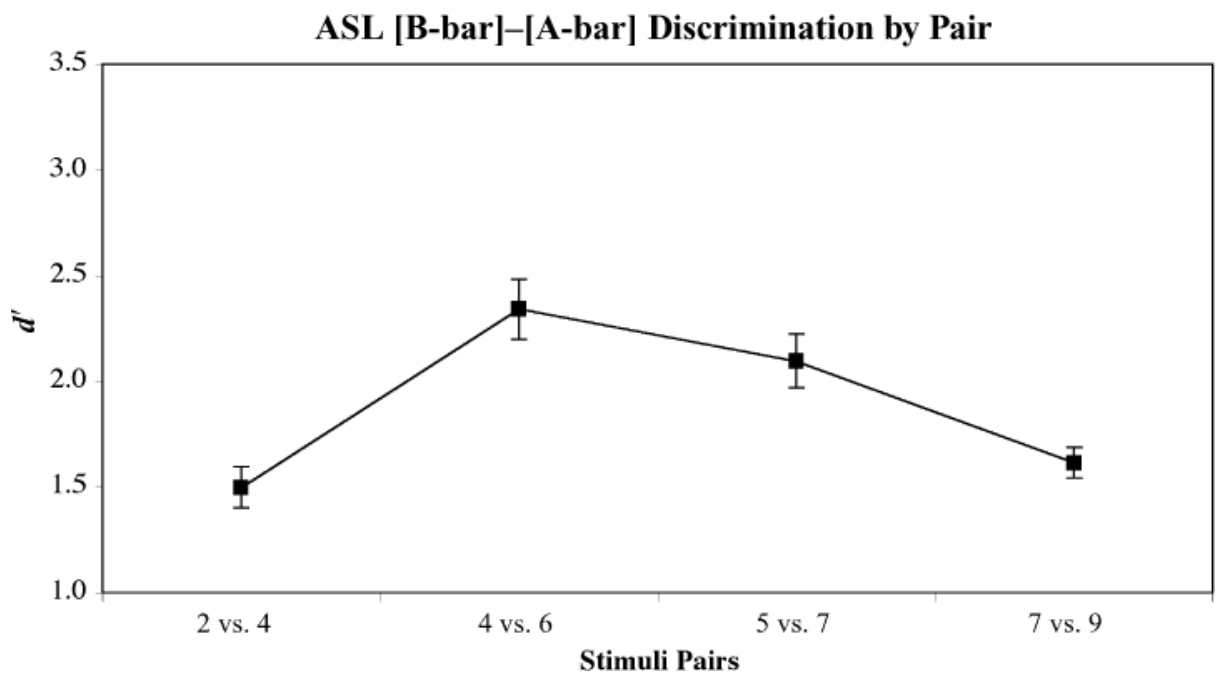

Figure 5B. The $d^{\prime}$ values by pair for the American Sign Language (ASL) group for the [B-bar][A-bar] continuum. 


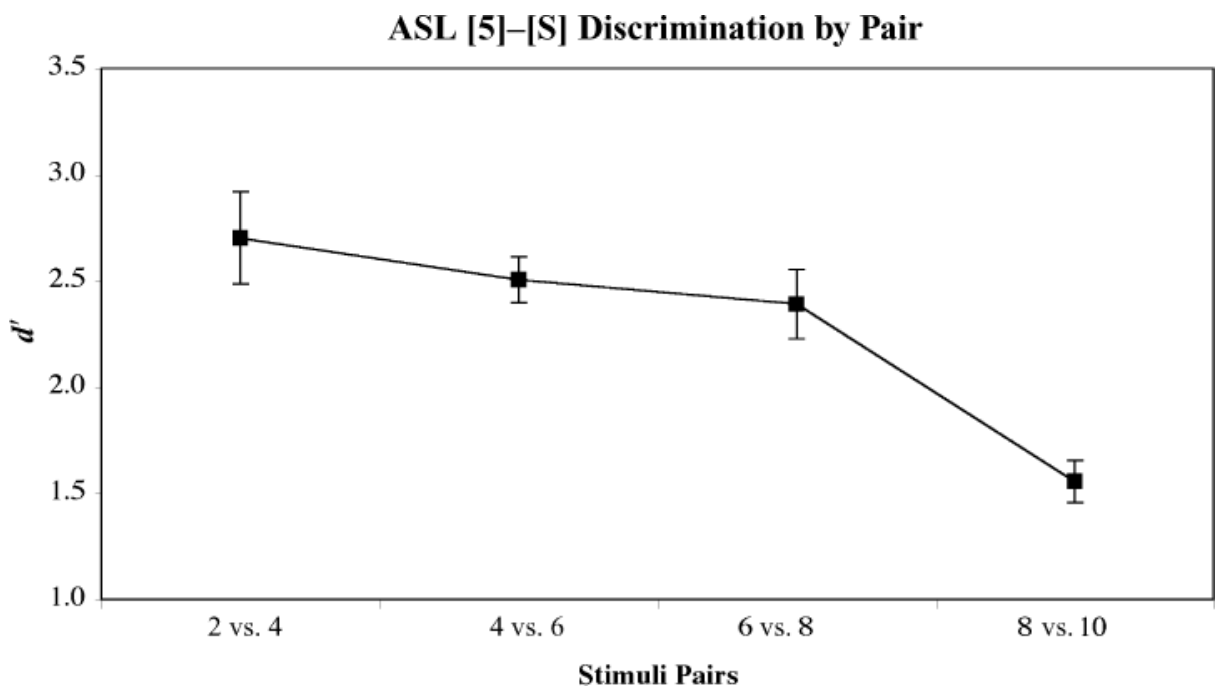

Figure 5C. The $d^{\prime}$ values by pair for the American Sign Language (ASL) group for the [5]-[S] continuum.

were especially revealing; here, only the deaf signers exhibited better discrimination across the category boundary, as compared with within-category discrimination, demonstrating $\mathrm{CP}$ for the [5]-[flat-0] and the [B-bar]-[Abar] contrasts. Furthermore, these CP effects were due to all of the within-category pairs being discriminated less well than the across-category pairs, so it was not the case that the $\mathrm{CP}$ effects were from only one end of the continuum or from certain handshape pairs along a continuum. The lack of CP effects for these handshape contrasts with nonsigners indicates that the enhanced discrimination at the category boundary for the deaf signers was not due solely to general properties of visual discrimination and perception. This pattern of results also corroborates and extends the findings of Emmorey et al.
(2003) involving, specifically, their use of phonemic hand configurations.

The lack of CP effects by the deaf signers for the [5]-[S] contrast pair was initially puzzling. However, closer inspection of this continuum (and an astute observation by a reviewer) revealed that there was a third phoneme category at the midpoint of the continuum, referred to as [hooked-5]. It was evident from the identification responses for the ASL group that they were noticing this intermediate category, since Variants 5 and 6 were identified as [5] roughly half of the time, indicating that they were guessing between the two extremes of [5] and [S], since neither was the correct choice. In addition, since the across-category stimuli for this continuum were most likely from within a new category ([hooked-5]), it fol-

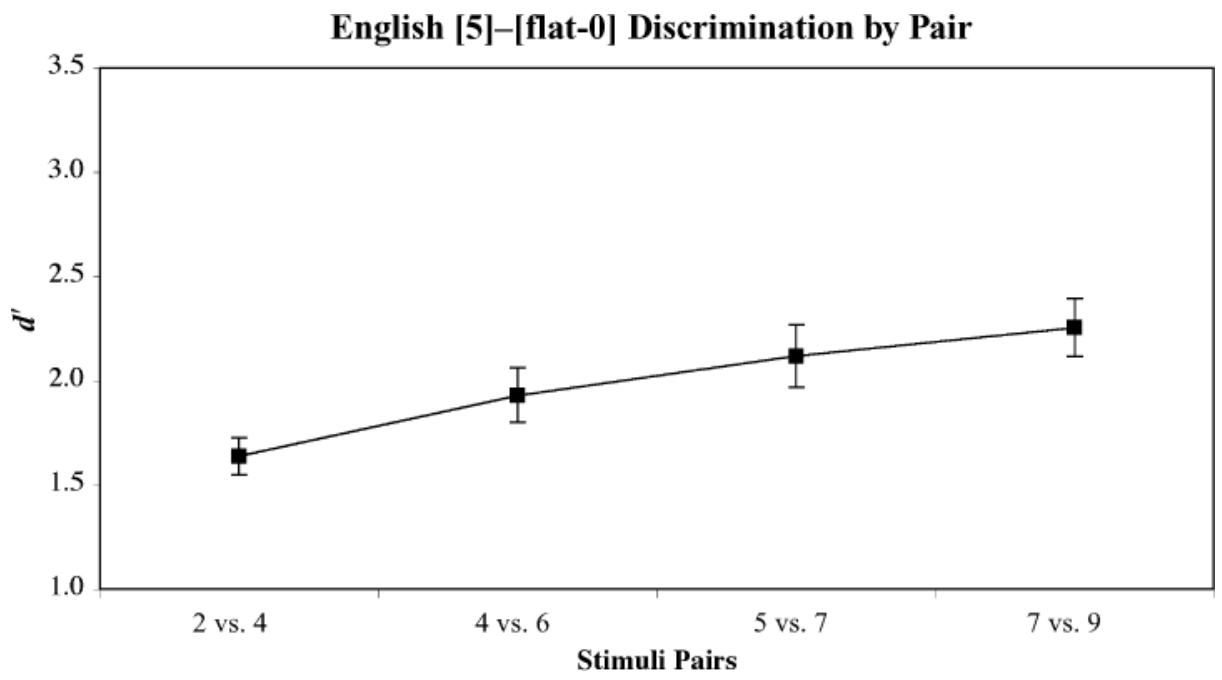

Figure 5D. The $d^{\prime}$ values by pair for the English group for the [5]-[flat-0] continuum. 


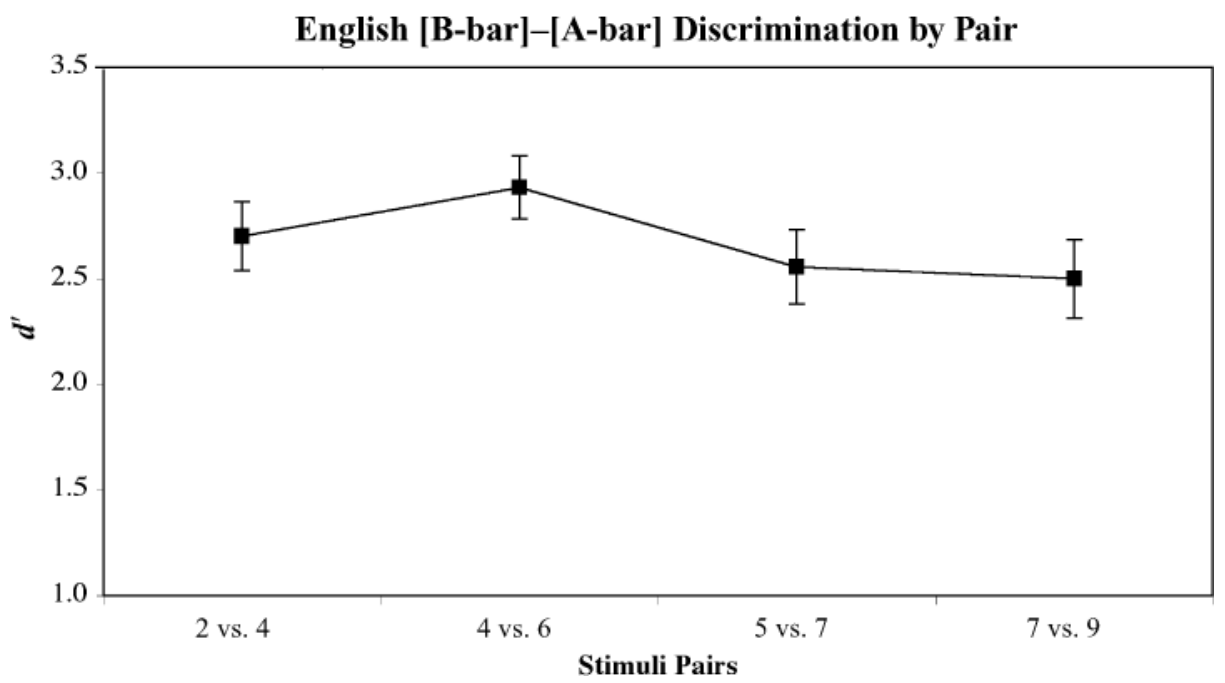

Figure 5E. The $d^{\prime}$ values by pair for the English group for the [B-bar]-[A-bar] continuum.

lows that the detection of these items was not enhanced, as compared with the stimuli that were designated as the within-category stimuli. For the individual pair analysis for this continuum, the discrimination scores were consistently high across the continuum and did not decrease significantly until the end of the continuum near [S]. This behavior is in accordance with the presence of a third category and lends support to the argument that the signers were using linguistic knowledge, rather than purely visual or perceptual knowledge, for this task: If linguistic experience were of no consequence for $\mathrm{CP}$, the extra phonemic category should not have affected the discrimination abilities of the ASL participants for this continuum.

There are several alternative interpretations for these results. The first is that although finding $\mathrm{CP}$ with the signers, but not with the nonsigners, does indicate an effect of experience, the type of experience may have been perceptual experience, rather than linguistic experience. We would argue, however, that the perceptual experience of using a language (receptively and/or expressively) involves a pairing between form and meaning, which is exactly what constitutes linguistic experience with a language. Teasing apart perceptual from linguistic processing remains an open topic for future research. What is clear, however, is that CP involves a unique interplay of linguistic and perceptual systems.

The second alternative is that although there was a difference in performance between the ASL and the English groups, this difference was a result of the ASL group's having visual expertise with the handshapes, and the difference was, therefore, one of familiarity. If visual

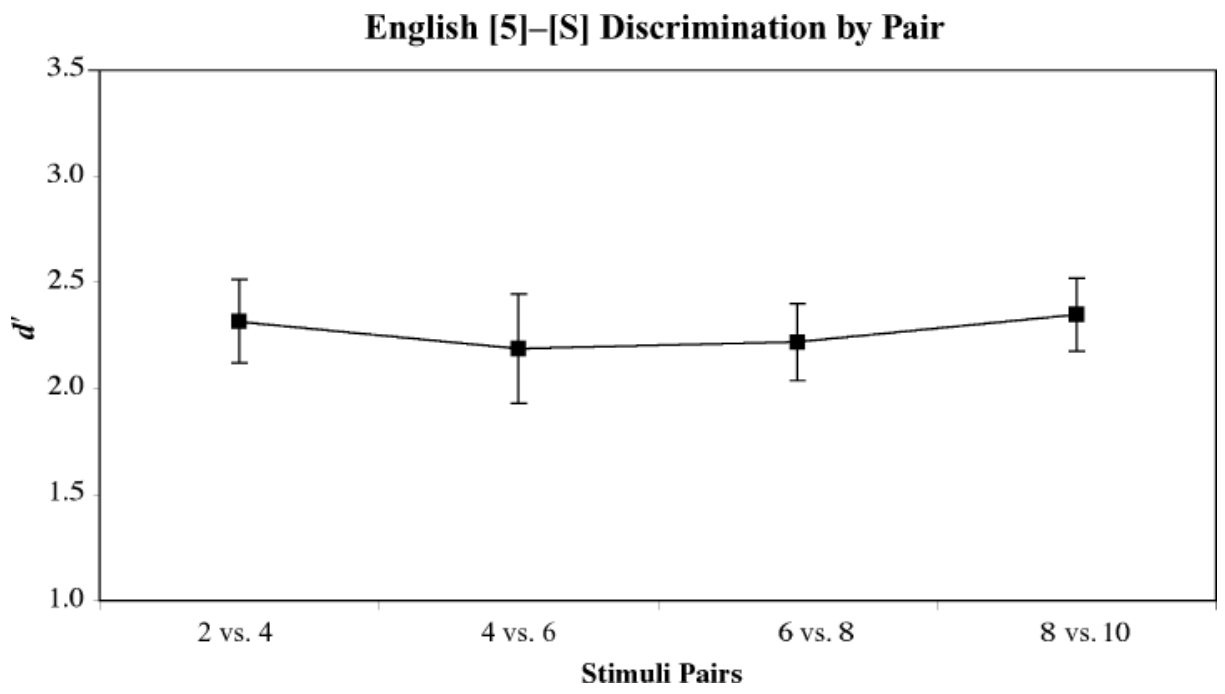

Figure 5F. The $d^{\prime}$ values by pair for the English group for the [5]-[S] continuum. 
expertise was guiding discrimination, the ASL group's performance should have been significantly better than the English group's performance for all of these contrasts as well, since the English group had no expertise in looking at the fine distinctions required for the handshapes. However, this was not what occurred for the discrimination task. The English group had very high performance at detecting the handshapes for all of the contrasts. Furthermore, the ASL group's performance was constrained by linguistic category membership: There was a sharp increase in their detection abilities for those pairs that cross a category boundary for the contrastive handshapes [5]-[flat-0] and [B-bar]-[A-bar]. Thus, visual expertise does not account for the differential performance between the ASL and the English groups.

The third alternative interpretation is that perhaps this differential performance between the two groups was simply due to well-learned categories exerting their influence on discrimination, and these categories need not have been linguistic in nature. Thus, signers simply have categories for this kind of perceptual input, and nonsigners do not. Although a label-learning hypothesis could potentially account for the present results, the results from several lines of research argue against this explanation. First, it has been demonstrated that certain animals and human infants categorically discriminate phonetic contrasts from speech (Dooling et al., 1995; Eimas et al., 1971; Jusczyk, 1997; Kluender et al., 1987; Kuhl, 1981, 1987; Kuhl \& Miller, 1975, 1978; Kuhl \& Padden, 1982, 1983; Ramus et al., 2000). Since neither animals nor human infants have relevant experience with the speech contrasts on which they are being tested, it is not possible that they have learned category labels for these contrasts.

Second, there is behavioral evidence from Baker, Golinkoff, and Petitto (2005) that 4-month-old hearing (speech-exposed) infants, who have no exposure to a signed language, can categorically discriminate phonetic handshape units in ASL. The infants also have no relevant experience with the handshape contrasts, which were a subset of the stimuli used in the present study, and thus cannot be using category labels for discrimination.

Third, more recent research on CP with color (Laws et al., 1995; Özgen \& Davies, 2002; Pilling et al., 2003; Roberson et al., 2000) indicates that CP for color is linguistically relevant, since CP effects were found for speakers only at the boundaries of their existing linguistic categories. Thus, the possession of linguistic categories, rather than the possession of perceptual category labels, facilitates recognition and influences perceptual judgments in a visual domain. The results from the present study with ASL, a visual language, parallel the color $\mathrm{CP}$ results and support an explanation of $\mathrm{CP}$ that is based on linguistic experience. For these reasons, we believe that a label-learning hypothesis does not explain the effects of language experience found in the present study.

A remaining topic regarding $\mathrm{CP}$ is how to reconcile the view that $\mathrm{CP}$ for language is mediated by linguistic experience (rather than being mediated solely by per- ception) with previous findings showing $\mathrm{CP}$ effects for language in animals, as well as CP for areas outside of language in humans. It thus is possible that common neural substrates that are rooted in general perception underlie CP. However, if this were so, we would remain puzzled by the following two observations concerning $\mathrm{CP}$ for language. First, we know that CP effects for language are contingent upon the experience that the organism receives; for example, a native adult speaker of Japanese does not exhibit CP for linguistic contrasts that are not found in the native language (Miyawaki et al., 1975). Second, CP for language exhibits universal developmental shifts in the perception of speech contrasts (see Jusczyk, 1997, for a review). However, for other types of CP in humans (e.g., that for faces and tones), as well as for CP for speech in animals, CP effects are not mediated by experience in the same way, since there is no developmental shift in the perception of these stimuli. Instead, linguistic $\mathrm{CP}$ appears to be more fragile, in the sense that the continuance of linguistic $\mathrm{CP}$ requires experience with the specific linguistic contrasts being tested. Whether or not CP for linguistic and nonlinguistic phenomena have an underlying neural similarity, however, is an exciting topic for future research.

In sum, we are encouraged by the results of the present study and argue that they provide a new perspective on the status of linguistic experience for $\mathrm{CP}$ effects, challenging the view that $\mathrm{CP}$ effects are the result of solely perceptual processing. Deaf signers appear to develop specialized abilities for perceiving handshapes in signed language, just as speakers do for perceiving speech. These results suggest that $\mathrm{CP}$ for language emerges naturally as a part of language processing, regardless of language modality, and that $\mathrm{CP}$ for language is mediated by linguistic experience.

\section{REFERENCES}

AsLin, R. N., \& Pisoni, D. B. (1980). Some developmental processes in speech perception. In G. H. Yeni-Komshian, J. F. Kavanagh, \& C. A Ferguson (Eds.), Child phonology: Vol. 2. Perception (pp. 67-96). New York: Academic Press.

Baker, S. A., Golinkoff, R. M., \& Petitto, L.-A. (2005). New insights into old puzzles from infants' discrimination of soundless phonetic units. Manuscript submitted for publication.

Battison, R. (1978). Lexical borrowing in American Sign Language. Silver Spring, MD: Linstok.

Beale, J. M., \& KeIL, F. C. (1995). Categorical effects in the perception of faces. Cognition, 57, 217-239.

Bornstein, M. H., \& KordA, N. O. (1984). Discrimination and matching within and between hues measured by reaction times: Some implications for categorical perception and levels of information processing. Psychological Research, 46, 207-222.

Boynton, R. M., Fargo, L., Olson, C. X., \& Smallman, H. S. (1989). Category effects in color memory. Color Research \& Application, 14, 229-234.

Brentari, D. (1995). Sign language phonology: ASL. In J. A. Goldsmith (Ed.), Handbook of phonological theory (pp. 615-639). Cambridge, MA: Blackwell.

Brentari, D. (1998). A prosodic model of sign language phonology. Cambridge, MA: MIT Press.

Calder, A. J., Young, A. W., Perrett, D. I., Etcoff, N. L., \& RowLAND, D. (1996). Categorical perception of morphed facial expressions. Visual Cognition, 3, 81-117. 
Campbell, R., Pascalis, O., Coleman, M. Wallace, S. B., \& BenSON, P. J. (1997). Are faces of different species perceived categorically by human observers? Proceedings of the Royal Society of London: Series B, 264, 1429-1434.

Campbell, R., Woll, B., Benson, P., \& Wallace, S. B. (1999). Categorical perception of face actions: Their role in sign language and in communicative facial displays. Quarterly Journal of Experimental Psychology, 52A, 67-95.

Cohen, J. D., MacWhinney, B., Flatt, M., \& Provost, J. (1993). PsyScope: A new graphic interactive environment for designing psychology experiments. Behavior Research Methods, Instruments, \& Computers, 25, 257-271.

Corina, D. P., \& SANDLER, W. (1993). On the nature of phonological structure in sign language. Phonology, 10, 165-207.

DAMPER, R. I., \& HARnad, S. R. (2000). Neural network models of categorical perception. Perception \& Psychophysics, 62, 843-867.

Dooling, R. J., Best, C. T., \& Brown, S. D. (1995). Discrimination of synthetic full-formant and sinewave /ra-la/ continua by budgerigars (Melopsittacus undulatus) and zebra finches (Taeniopygia guttata). Journal of the Acoustical Society of America, 97, 1839-1846.

EImas, P. D. (1975). Developmental studies in speech perception. In L. B. Cohen \& P. Salapatek (Eds.), Infant perception: From sensation to cognition (Vol. 2, pp. 193-231). New York: Academic Press.

Eimas, P. D., Siqueland, E. R., JusczyK, P., \& Vigorito, J. (1971). Speech perception in infants. Science, 171, 303-306.

Emmorey, K., McCullough, S., \& Brentari, D. (2003). Categorical perception in American Sign Language. Language \& Cognitive Processes, 18, 21-45.

Etcoff, N. L., \& Magee, J. J. (1992). Categorical perception of facial expressions. Cognition, 44, 227-240.

GreEn, D. M., \& SwETs, J. (1966). Signal detection theory and psychophysics. New York: Wiley.

JUSCZYK, P. W. (1997). The discovery of spoken language. Cambridge, MA: MIT Press.

Jusczyk, P. W., Rosner, B. S., Cutting, J. E., Foard, C. F., \& Smith, L. B. (1977). Categorical perception of nonspeech sounds by 2-monthold infants. Perception \& Psychophysics, 21, 50-54.

Kluender, K. R., Diehl, R. L., \& Killeen, P. R. (1987). Japanese quail can learn phonetic categories. Science, 237, 1195-1197.

KUHL, P. K. (1981). Discrimination of speech by nonhuman animals: Basic auditory sensitivities conducive to the perception of speechsound categories. Journal of the Acoustical Society of America, 70, 340-349.

KuHL, P. K. (1987). The special-mechanisms debate in speech research: Categorization tests on animals and infants. In S. Harnad (Ed.), Categorical perception: The groundwork of cognition (pp. 355-386). Cambridge: Cambridge University Press.

KuHL, P. K. (2000). A new view of language acquisition. Proceedings of the National Academy of Sciences, 97, 11850-11857.

KuHL, P. K., \& Miller, J. D. (1975). Speech perception by the chinchilla: Voiced-voiceless distinction in alveolar plosive consonants. Science, 190, 69-72.

KuHL, P. K., \& Miller, J. D. (1978). Speech perception by the chinchilla: Identification function for synthetic VOT stimuli. Journal of the Acoustical Society of America, 63, 905-917.

KuHL, P. K., \& PADDEN, D. M. (1982). Enhanced discriminability at the phonetic boundaries for the voicing feature in macaques. Perception \& Psychophysics, 32, 542-550.

KuHL, P. K., \& PADDEn, D. M. (1983). Enhanced discriminability at the phonetic boundaries for the place feature in macaques. Journal of the Acoustical Society of America, 73, 1003-1010.

Lane, H., Boyes-Braem, P., \& Bellugi, U. (1976). Preliminaries to a distinctive feature analysis of handshapes in American Sign Language. Cognitive Psychology, 8, 263-289.

LaWS, G., DaVIES, I., \& ANDREWS, C. (1995). Linguistic structure and non-linguistic cognition: English and Russian blues compared. Language \& Cognitive Processes, 10, 59-94.

Liberman, A. M. (1957). Some results of research on speech perception. Journal of the Acoustical Society of America, 29, 117-123.

Liberman, A. M. (1996). Speech: A special code. Cambridge, MA: MIT Press.
Macmillan, N. A., \& Creelman, C. D. (1991). Detection theory: A user's guide. Cambridge: Cambridge University Press.

Massaro, D. W. (1987). Speech perception by ear and eye: A paradigm for psychological inquiry. Hillsdale, NJ: Erlbaum.

Miyawaki, K., Strange, W., Verbrugge, R., Liberman, A. M., JenkINS, J. J., \& FuJIMURA, O. (1975). An effect of linguistic experience: The discrimination of [r] and [1] by native speakers of Japanese and English. Perception \& Psychophysics, 18, 331-340.

NewPort, E. L. (1982). Task specificity in language learning? Evidence from speech perception and American Sign Language. In E. Wanner \& L. R. Gleitman (Eds.), Language acquisition: The state of the art (pp. 450-486). Cambridge: Cambridge University Press.

ÖzGEN, E., \& DAVIES, I. R. L. (2002). Acquisition of categorical color perception: A perceptual learning approach to the linguistic relativity hypothesis. Journal of Experimental Psychology: General, 131, 477-493.

Petitto, L.-A., Holowka, S., Sergio, L., \& Ostry, D. (2001). Language rhythms in baby hand movements. Nature, 413, 35-36.

Petitto, L.-A., Zatorre, R., Gauna, K., Nikelski, E. J., Dostie, D., \& Evans, A. (2000). Speech-like cerebral activity in profoundly deaf people processing signed languages: Implications for the neural basis of human language. Proceedings of the National Academy of Sciences, 97, 13961-13966.

Pilling, M., Wiggett, A., Özgen, E., \& Davies, I. R. L. (2003). Is color "categorical perception" really perceptual? Memory \& Cognition, 31, 538-551.

PISONI, D. B. (1977). Identification and discrimination of relative onset time of two component tones: Implications for voicing perceptions in stops. Journal of the Acoustical Society of America, 61, 1352-1361.

PolKa, L., \& Werker, J. F. (1994). Developmental changes in perception of nonnative vowel contrasts. Journal of Experimental Psychology, 20, 421-435.

Ramus, F., Hauser, M. D., Miller, C., Morris, D., \& Mehler, J. (2000). Language discrimination by human newborns and cotton-top tamarin monkeys. Science, 288, 349-351.

Roberson, D., Davies, I., \& Davidoff, J. (2000). Color categories are not universal: Replications and new evidence from a stone-age culture. Journal of Experimental Psychology: General, 129, 369-398.

SANDLER, W. (1986). The spreading hand autosegment of American Sign Language. Sign Language Studies, 50, 1-28.

SANDLER, W. (1996). Representing handshapes. International Review of Sign Language Linguistics, 1, 115-158.

Stokoe, W. C. (1960). Sign language structure: An outline of the visual communication systems of the American deaf (Studies in Linguistics: Occasional Paper 8). Buffalo: University of Buffalo. (Revised 1978 Silver Spring, MD: Linstok).

Stokoe, W. C., Casterline, D., \& Cronenberg, C. (1965). A dictionary of American Sign Language on linguistic principles. Washington, DC: Gallaudet College Press.

Supalla, T., \& NeWPORT, E. L. (1975). In search of categorical perception in sign. Unpublished manuscript, University of California, San Diego.

TAJFEL, H., \& Wilkes, A. L. (1963). Classification and quantitative judgment. British Journal of Psychology, 54, 101-114.

VAN DER HulST, H. (1995). The composition of handshapes. In Working papers in linguistics (Vol. 23, pp. 1-17). Trondheim: University of Trondheim, Department of Linguistics.

Werker, J. F., Gilbert, J. H., Humphrey, K., \& Tees, R. C. (1981). Developmental aspects of cross-language speech perception. Child Development, 52, 349-355.

Werker, J. F., \& Tees, R. C. (1983). Developmental changes across childhood in the perception of nonnative speech sounds. Canadian Journal of Psychology, 37, 278-286.

Young, A. W., Rowland, D., Calder, A. J., Etcoff, N. L., Seth, A., \& Perrett, D. I. (1997). Facial expression megamix: Tests of dimensional and category accounts of emotion recognition. Cognition, 63, 271-313.

\section{NOTES}

1. The phonological structure of a sign consists of four components (often called parameters), which are roughly analogous to features: 
(1) location, or where the hand is located in relation to the body (e.g., head, chin, nose, or chest); (2) movement, or how the hand moves in space (e.g., circle, arc, or wiggle fingers); (3) handshape, the actual form of the hand itself (e.g., 5, A, or G); and (4) orientation, the direction the palm of the hand is facing in relation to the body (e.g., palm facing body, palm to side, or palm out) (Battison, 1978; Stokoe, 1960; Stokoe, Casterline, \& Cronenberg, 1965). These four components combine simultaneously in order to produce a sign that has meaning. The components are regarded as separate, despite their simultaneous combination, since as in oral language, there are minimal pairs in the language that differ by only one component (see Brentari, 1995, for examples of minimal pairs). It should also be noted that although any of these parameters could be subjected to CP analyses, only location and handshape have been studied thus far, and $\mathrm{CP}$ effects have been found only for handshape.

2. Hand configuration is the terminology used by Emmorey et al. (2003). Handshape is the terminology used in this article; although handshape is most commonly employed, both terms can be found in the literature. Crucially, both terms refer to the identical level of language organization (phonetic/phonological); in particular, both terms make reference to the specific phonetic form of the hand in a sign.

3. The specific stimuli that Emmorey et al. (2003) used consisted of the following: two phonemic hand configuration continua (i.e., the hand configurations serve to provide a difference in meaning, as in a minimal pair), one from the sign for PLEASE to the sign for SORRY and the other from the sign for MOTHER to the sign for POSH; one allophonic handshape continuum (i.e., the hand configurations do not serve to provide a difference in meaning), from open- $N$ to closed- $N$ in the sign for SAY-NO-TO; two phonemic place of articulation continua, one from the sign for ONION to the sign for APPLE, and the other from the sign for YESTERDAY to the sign for HANGOVER; and one allophonic place of articulation continuum, from the chin to the back jaw in the sign for DEAF.

4. This method of using individual participant boundaries to set the discrimination pairs was chosen solely to ensure the most accurate discrimination scores. There is no way to decide a priori where an individual will set the boundary for a given continuum or that all participants will set the boundary in exactly the same place. In addition, there were no assumptions made about the type of underlying categorical representations that the participants would be using for this task, since there has been some discussion in the literature about the identification task and whether participants are accessing a representation for the stimulus that is based on perceptual features or one that is based on category membership (Damper \& Harnad, 2000; Massaro, 1987). It is equally possible that both groups were sorting on the basis of perceptual representations or that the English group was sorting on the basis of perceptual representations and the ASL group was sorting on the basis of categorical representations, since these handshapes are from linguistic phonetic categories present in their native language.

5. A notable difference between the present study and Emmorey et al.'s (2003) study is the type of data analysis employed, whereby they used an averaging approach. In the averaging technique used, Emmorey et al. analyzed the labeling (identification) data by identifying the category boundary as those images that had labeling percentages between $33 \%$ and $66 \%$. The discrimination data were analyzed by taking the mean accuracy for the pair of images located at the category boundary and comparing that with the mean accuracy for all of the other pairs of images combined. In addition, an analysis of the response variability for participant discrimination of the hand configurations was conducted, using Levene's test of homogeneity of variance. These analysis methods were employed so that Emmorey et al.'s results could be compared with those in existing studies of visual $\mathrm{CP}$, notably leaving absent any comparisons with adult speech $\mathrm{CP}$.

6. It should be noted that the [B-bar]-[A-bar] continuum was the same phonemic handshape continuum used by Emmorey et al. (2003), whereas the [5]-[flat-0] and [5]-[S] continua were unique to the present study. In addition, in the present study, the handshapes were presented in neutral space in order to avoid the participants' accessing lexical semantic (meaningful) information (as opposed to Emmorey et al.'s study, in which the handshapes were presented over the actual body locations of the signs). The present study also employed more natural moving handshapes (as opposed to the static handshapes used by Emmorey et al.).

7. Following standard phonetic continua that consist of 2 endpoints and 9 intermediate variants (e.g., Emmorey et al., 2003), we also constructed an 11-step continuum for each of the handshape contrasts. To ensure that the variants along the continuum were equidistant, we conducted a three-phase pilot test on 5 adult signers. In Phase 1, we identified the endpoint handshapes of each continuum by taking anatomical measurements from the base of the palm to the tips of each finger for each participant. We then calculated the total distance between the endpoints and divided that distance equally among the 9 intermediate variants (the range across all participants and handshape continua was between 1.0 and $1.2 \mathrm{~cm}$ ). Finally, these measurements were mapped onto a template that the participants used as the guide for their handshape variant production in Phase 2. In Phase 2, the signers used the template to form each of the 11 variants, which were videotaped, and then each individual variant was made into a still image. In Phase 3, the signers made the natural movement of starting with the fully open endpoint and then closing the hand to the fully closed endpoint in one continuous motion, at normal speed and also in slow motion (22-24 sec, and $1 \mathrm{~min}$ $7 \mathrm{sec}$ to $1 \mathrm{~min} 11 \mathrm{sec}$, respectively). To ensure a standard interval that would produce a predictable handshape change, the total time for each of the speeds of movement was calculated and then divided by 11 (1-2 frames and 4-5 frames, respectively). Still images were made for each variant by advancing through the continuous motion clip at the given frame range. These images were then compared with the template still images, to be sure that the variants were the same across the continuum for all three handshape continua and across all 5 signers.

8. Note that due to variable boundary placement by the participants, the two central pairs are elevated in relation to the remaining end pairs, rather than having one peak pair for the continuum that is the acrosscategory pair. 
APPENDIX A

Participant Boundary Locations by Continuum

\begin{tabular}{cccc}
\hline Participant & [5]-[flat-0] & [B-bar]-[A-bar] & {$[5]-[S]$} \\
\hline 1 & 5.0 & 4.5 & 5.5 \\
2 & 5.5 & 5.5 & 4.5 \\
3 & 6.0 & 5.5 & 6.5 \\
4 & 5.0 & 4.5 & 4.0 \\
5 & 5.5 & 4.5 & 6.5 \\
6 & 6.5 & 6.5 & 7.5 \\
7 & 5.5 & 4.5 & 5.0 \\
8 & 5.0 & 4.5 & 4.5 \\
9 & 4.5 & 4.5 & 4.5 \\
10 & 4.5 & 5.5 & 6.5 \\
11 & 5.5 & 6.5 & 6.5 \\
12 & 5.5 & 5.5 & 6.5 \\
13 & 5.5 & 4.5 & 6.0 \\
14 & 5.5 & 6.5 & 6.5 \\
15 & 5.5 & 5.5 & 7.5 \\
16 & 4.5 & 5.5 & 4.5 \\
17 & 5.0 & 5.5 & 4.5 \\
18 & 4.5 & 6.5 & 7.5 \\
19 & 5.5 & 6.5 & 6.5 \\
20 & 5.5 & 6.5 & 7.5 \\
21 & 5.5 & 5.5 & 6.5 \\
22 & 5.5 & 6.5 & 6.5 \\
23 & 5.5 & 5.5 & 6.5 \\
24 & 5.5 & 5.5 & 6.5 \\
25 & 5.5 & 5.5 & 7.5 \\
26 & 5.5 & 6.5 & 7.5 \\
27 & 5.5 & 5.5 & 7.0 \\
28 & 5.5 & 5.5 & 5.0 \\
29 & 5.5 & 5.5 & 6.5 \\
30 & 5.0 & 5.5 & 7.0 \\
\hline
\end{tabular}

Note-ASL group, Participants 1-15; English group, Participants $16-30$.

APPENDIX B

Handshape Pair Statistical $p$ Values $(\alpha=.01)$

\begin{tabular}{|c|c|c|c|c|c|c|}
\hline Group & Contrast & Pairs & $2-4$ & $4-6$ & $5-7$ & $7-9$ \\
\hline \multirow[t]{8}{*}{ ASL } & {$[5-0]$} & $2-4$ & - & .001 & .001 & .033 \\
\hline & & $4-6$ & .001 & - & .012 & .006 \\
\hline & & $5-7$ & .001 & .012 & - & .001 \\
\hline & & $7-9$ & .033 & .006 & .001 & - \\
\hline & {$[\mathrm{B}-\mathrm{A}]$} & $2-4$ & - & .001 & .001 & .266 \\
\hline & & $4-6$ & .001 & - & .058 & .001 \\
\hline & & $5-7$ & .001 & .058 & - & .001 \\
\hline & & $7-9$ & .266 & .001 & .001 & - \\
\hline \multirow[t]{9}{*}{ ENG } & [5-0] & $2-4$ & - & .049 & .008 & .001 \\
\hline & & $4-6$ & .049 & - & .002 & .001 \\
\hline & & $5-7$ & .008 & .002 & - & .018 \\
\hline & & $7-9$ & .001 & .001 & .018 & - \\
\hline & {$[\mathrm{B}-\mathrm{A}]$} & $2-4$ & - & .019 & .228 & .102 \\
\hline & & $4-6$ & .019 & - & .003 & .002 \\
\hline & & $5-7$ & .228 & .003 & - & .223 \\
\hline & & $7-9$ & .102 & .002 & .223 & - \\
\hline & & & $2-4$ & 4-6 & $6-8$ & $8-10$ \\
\hline \multirow[t]{4}{*}{ ASL } & [5-S] & $2-4$ & - & .390 & .029 & .001 \\
\hline & & $4-6$ & .390 & - & .398 & .001 \\
\hline & & $6-8$ & .029 & .398 & - & .001 \\
\hline & & $8-10$ & .001 & .001 & .001 & - \\
\hline \multirow[t]{4}{*}{ ENG } & {$[5-\mathrm{S}]$} & $2-4$ & - & .400 & .372 & .747 \\
\hline & & 4-6 & .400 & - & .786 & .281 \\
\hline & & $6-8$ & .029 & .786 & - & .017 \\
\hline & & $8-10$ & .747 & .281 & .017 & - \\
\hline
\end{tabular}


APPENDIX C

$d^{\prime}$ Values by Pair for Individual Participants

\begin{tabular}{|c|c|c|c|c|c|c|c|c|c|c|c|c|}
\hline Participant & $\begin{array}{l}{[5-0]} \\
(2-4)\end{array}$ & $\begin{array}{l}{[5-0]} \\
(4-6)\end{array}$ & $\begin{array}{l}{[5-0]} \\
(5-7)\end{array}$ & $\begin{array}{l}{[5-0]} \\
(7-9)\end{array}$ & $\begin{array}{c}{[\mathrm{B}-\mathrm{A}]} \\
(2-4)\end{array}$ & $\begin{array}{c}{[\mathrm{B}-\mathrm{A}]} \\
(4-6)\end{array}$ & $\begin{array}{c}{[\mathrm{B}-\mathrm{A}]} \\
(5-7)\end{array}$ & $\begin{array}{c}{[\mathrm{B}-\mathrm{A}]} \\
(7-9)\end{array}$ & $\begin{array}{l}{[5-\mathrm{S}]} \\
(2-4)\end{array}$ & $\begin{array}{l}{[5-\mathrm{S}]} \\
(4-6)\end{array}$ & $\begin{array}{l}{[5-\mathrm{S}]} \\
(6-8)\end{array}$ & $\begin{array}{r}{[5-\mathrm{S}]} \\
(8-10) \\
\end{array}$ \\
\hline 1 & 1.58 & 2.05 & 2.45 & 1.84 & 0.93 & 2.75 & 1.49 & 1.34 & 3.19 & 2.65 & 2.57 & 1.83 \\
\hline 2 & 1.10 & 1.79 & 1.84 & 1.55 & 1.84 & 2.17 & 2.12 & 1.49 & 3.24 & 3.24 & 3.44 & 1.32 \\
\hline 3 & 1.58 & 1.68 & 2.15 & 1.57 & 0.93 & 1.72 & 1.71 & 1.45 & 2.83 & 2.27 & 1.76 & 1.13 \\
\hline 4 & 1.03 & 2.57 & 3.00 & 1.84 & 0.93 & 1.99 & 1.73 & 1.60 & 3.59 & 2.65 & 2.79 & 1.59 \\
\hline 5 & 0.36 & 2.08 & 2.43 & 2.03 & 1.78 & 3.35 & 2.29 & 1.72 & 1.90 & 3.19 & 2.09 & 1.29 \\
\hline 6 & 1.27 & 1.60 & 1.74 & 1.38 & 1.49 & 2.28 & 2.29 & 1.92 & 3.24 & 2.65 & 2.96 & 2.10 \\
\hline 7 & 1.49 & 1.54 & 1.94 & 1.65 & 1.51 & 2.12 & 1.80 & 1.76 & 3.24 & 2.77 & 3.09 & 1.10 \\
\hline 8 & 0.16 & 2.46 & 2.77 & 1.80 & 1.84 & 1.99 & 1.55 & 1.17 & 2.83 & 2.65 & 2.81 & 1.03 \\
\hline 9 & 1.10 & 2.04 & 1.87 & 1.36 & 1.84 & 2.10 & 2.21 & 1.69 & 2.83 & 2.28 & 2.45 & 1.32 \\
\hline 10 & 1.73 & 1.94 & 1.50 & 1.55 & 1.19 & 1.50 & 1.40 & 1.01 & 3.24 & 2.16 & 2.36 & 1.65 \\
\hline 11 & 2.17 & 2.81 & 3.16 & 2.63 & 1.10 & 2.02 & 2.41 & 1.84 & 3.59 & 2.53 & 2.90 & 1.66 \\
\hline 12 & 1.03 & 1.60 & 1.79 & 1.78 & 1.57 & 2.81 & 3.16 & 1.57 & 0.93 & 2.23 & 1.48 & 1.27 \\
\hline 13 & 2.17 & 2.69 & 3.08 & 2.91 & 1.84 & 3.31 & 2.66 & 1.97 & 1.20 & 1.96 & 1.20 & 1.80 \\
\hline 14 & 2.12 & 2.42 & 2.42 & 1.36 & 1.90 & 2.20 & 2.06 & 1.89 & 2.90 & 1.66 & 2.01 & 2.04 \\
\hline 15 & 1.58 & 2.31 & 2.34 & 1.49 & 1.80 & 2.83 & 2.57 & 1.82 & 1.78 & 2.68 & 1.96 & 2.22 \\
\hline 16 & 1.57 & 1.68 & 1.85 & 2.09 & 2.90 & 3.35 & 2.93 & 2.80 & 2.22 & 2.01 & 2.39 & 2.62 \\
\hline 17 & 1.58 & 1.68 & 1.71 & 1.73 & 1.84 & 2.41 & 2.38 & 2.28 & 2.83 & 2.16 & 2.20 & 2.28 \\
\hline 18 & 1.78 & 1.78 & 2.10 & 2.36 & 2.04 & 2.38 & 1.62 & 1.65 & 2.04 & 2.51 & 2.25 & 2.09 \\
\hline 19 & 2.17 & 2.06 & 2.05 & 2.57 & 2.04 & 2.41 & 2.03 & 1.68 & 2.12 & 2.12 & 1.98 & 2.05 \\
\hline 20 & 0.96 & 2.08 & 1.98 & 1.96 & 3.24 & 3.02 & 2.83 & 2.55 & 3.24 & 3.17 & 2.88 & 2.88 \\
\hline 21 & 1.49 & 1.04 & 1.50 & 1.43 & 2.42 & 2.42 & 2.54 & 2.79 & 1.90 & 2.34 & 2.69 & 2.71 \\
\hline 22 & 1.84 & 2.31 & 2.57 & 2.61 & 2.83 & 3.02 & 2.38 & 2.45 & 2.54 & 2.54 & 2.45 & 2.48 \\
\hline 23 & 1.90 & 1.89 & 2.05 & 2.36 & 2.83 & 2.79 & 2.21 & 2.35 & 0.93 & 1.00 & 1.17 & 1.19 \\
\hline 24 & 1.29 & 1.66 & 1.87 & 1.92 & 2.54 & 2.28 & 2.12 & 1.96 & 2.42 & 1.19 & 1.80 & 2.11 \\
\hline 25 & 2.03 & 1.51 & 1.50 & 1.69 & 2.12 & 2.45 & 2.54 & 2.26 & 2.12 & 1.84 & 1.94 & 2.06 \\
\hline 26 & 1.90 & 2.92 & 3.33 & 3.10 & 3.59 & 3.87 & 4.23 & 4.28 & 2.17 & 2.57 & 2.69 & 2.78 \\
\hline 27 & 1.65 & 2.88 & 3.39 & 3.47 & 2.90 & 3.35 & 2.83 & 2.92 & 1.49 & 1.65 & 1.29 & 1.42 \\
\hline 28 & 1.90 & 2.20 & 2.16 & 2.41 & 3.95 & 4.21 & 3.62 & 3.49 & 3.95 & 4.21 & 3.62 & 3.90 \\
\hline 29 & 1.20 & 1.80 & 2.10 & 2.10 & 3.24 & 3.02 & 2.29 & 2.37 & 3.19 & 3.35 & 2.83 & 2.90 \\
\hline 30 & 1.29 & 1.45 & 1.58 & 2.01 & 2.04 & 3.02 & 1.80 & 1.66 & 1.58 & 0.16 & 1.09 & 1.74 \\
\hline
\end{tabular}

Note-ASL group, Participants 1-15; English group, Participants 16-30.

(Manuscript received July 3, 2003;

revision accepted for publication August 24, 2004.) 